\title{
alpha-Pinene Autoxidation Products May Not Have Extremely Low Saturation Vapor Pressures Despite High O:C Ratios
}

Kurten, Theo

2016-04-28

Kurten , T, Tiusanen , K, Roldin , P , Rissanen , M , Luy , J-N , Boy , M , Ehn , M \& Donahue , N 2016 , ' alpha-Pinene Autoxidation Products May Not Have Extremely Low Saturation Vapor Pressures Despite High O:C Ratios ', Journal of Physical Chemistry A, vol. 120 , no. 16 , pp. 2569-2582 . https://doi.org/10.1021/acs.jpca.6b02196

http://hdl.handle.net/10138/318934

https://doi.org/10.1021/acs.jpca.6b02196

acceptedVersion

Downloaded from Helda, University of Helsinki institutional repository.

This is an electronic reprint of the original article.

This reprint may differ from the original in pagination and typographic detail.

Please cite the original version. 
This document is confidential and is proprietary to the American Chemical Society and its authors. Do not copy or disclose without written permission. If you have received this item in error, notify the sender and delete all copies.

\section{a-pinene Autoxidation Products May Not Have Extremely Low Saturation Vapor Pressures Despite High O:C Ratios}

\begin{tabular}{|r|l|}
\hline Journal: & The Journal of Physical Chemistry \\
\hline Manuscript ID & jp-2016-02196v.R1 \\
\hline Manuscript Type: & Article \\
\hline Date Submitted by the Author: & $\mathrm{n}$ /a \\
\hline Complete List of Authors: & $\begin{array}{l}\text { Kurtén, Theo; University of Helsinki, Department of Chemistry } \\
\text { Tiusanen, Kirsi; University of Helsinki, Department of Chemistry } \\
\text { Roldin, Pontus; Lund University, Division of Nuclear Physics } \\
\text { Rissanen, Matti; University of Helsinki, Physics } \\
\text { Luy, Jan-Niclas; Philipps-Universität Marburg, Fachbereich Chemie; } \\
\text { University of Helsinki, Department of Chemistry } \\
\text { Boy, Michael; University of Helsinki, Department of Physical Sciences } \\
\text { Ehn, Mikael; University of Helsinki, Department of Physical Sciences, } \\
\text { Donahue, Neil; Carnegie Mellon University, Center for Atmospheric Particle } \\
\text { Studies }\end{array}$ \\
\hline
\end{tabular}

\section{SCHOLARONE ${ }^{\text {Tw }}$}

Manuscripts 


\title{
a-pinene Autoxidation Products May not Have
}

\section{Extremely Low Saturation Vapor Pressures Despite High O:C Ratios}

\author{
Theo Kurtén ${ }^{1}$, Kirsi Tiusanen ${ }^{1}$, Pontus Roldin ${ }^{2,3}$, Matti Rissanen $^{2}$, Jan-Niclas Luy ${ }^{1,4}$, Michael \\ Boy $^{2}$, Mikael Ehn' ${ }^{2}$ Neil Donahue \\ ${ }^{1}$ Department of Chemistry, University of Helsinki, P.O. Box 55, FIN-00014, Helsinki, Finland \\ ${ }^{2}$ Department of Physics, University of Helsinki P.O. Box 64, FIN-00014, Helsinki, Finland \\ ${ }^{3}$ Division of Nuclear Physics, Lund University, P.O Box 118, SE-22100, Lund, Sweden \\ ${ }^{4}$ Fachbereich Chemie, Philipps Universität Marburg, Hans-Meerwein-Straße 4, D-35032 \\ Marburg, Germany. \\ ${ }^{5}$ Department of Chemical Engineering, Carnegie Mellon University, Pittsburgh, Pennsylvania \\ 15213-3890, United States
}




\section{ABSTRACT}

COSMO-RS (COnductor-like Screening MOdel for Real Solvents) and three different groupcontribution methods were used to compute saturation (subcooled) liquid vapor pressures for 16 possible products of ozone-initiated $\alpha$-pinene autoxidation, with elemental compositions $\mathrm{C}_{10} \mathrm{H}_{16} \mathrm{O}_{4-10}$ and $\mathrm{C}_{20} \mathrm{H}_{30} \mathrm{O}_{10-12}$. The saturation vapor pressures predicted by the different methods varied widely. COSMO-RS predicted relatively high saturation vapor pressures values in the range of $10^{-6}$ to $10^{-10}$ bar for the $\mathrm{C}_{10} \mathrm{H}_{16} \mathrm{O}_{4-10}$ "monomers", and $10^{-11}$ to $10^{-16}$ bar for the $\mathrm{C}_{20} \mathrm{H}_{30} \mathrm{O}_{10-12}$ "dimers". The group-contribution methods predicted significantly (up to 8 order of magnitude) lower saturation vapor pressures for most of the more highly oxidized monomers. For the dimers, the COSMO-RS predictions were within the (wide) range spanned by the three group-contribution methods. The main reason for the discrepancies between the methods is likely that the group-contribution methods do not contain the necessary parameters to accurately treat autoxidation products containing multiple hydroperoxide, peroxy acid or peroxide functional groups, which form intramolecular hydrogen bonds with each other. While the COSMO-RS saturation vapor pressures for these systems may be overestimated, the results strongly indicate that despite their high $\mathrm{O}: \mathrm{C}$ ratios, the volatility of the autoxidation products of a-pinene (and possibly other atmospherically relevant alkenes) are not necessarily extremely low. In other words, while autoxidation products are able to adsorb onto aerosol particles, their evaporation back into the gas phase cannot be assumed to be negligible, especially from the smallest nanometer-scale particles. Their observed effective contribution to aerosol particle growth may therefore involve rapid heterogeneous reactions (reactive uptake) rather than effectively irreversible physical absorption. 


\section{Introduction}

Conversion of volatile organic compounds (VOC) into less-volatile products is a major topic in atmospheric chemistry. Organic vapors, often classified by volatility into subgroups such as semi-volatile (SVOC), low-volatility (LVOC) or extremely low-volatility (ELVOC) organic compounds $^{1}$, are responsible for the formation of secondary organic aerosol (SOA). ${ }^{2}$ Aerosol particles, of which SOA is a key component, in turn play a significant role in regulating Earth's climate, and are responsible for most air-pollution related mortality and other adverse health effects. $^{3}$

The main chemical mechanism responsible for the formation of low-volatility material in the atmosphere is the addition of polar oxygen-containing functional groups to a carbon backbone through oxidation reactions. ${ }^{4,5}$ Oxidation of closed-shell molecules in the troposphere is always initiated by radical formation, which can occur either via direct photolysis, or (more commonly) via reaction with one of a small number of photochemically generated oxidants, such as $\mathrm{OH}, \mathrm{O}_{3}$, $\mathrm{Cl}$ and $\mathrm{NO}_{3} .{ }^{6}$ The resulting radicals almost always then react with molecular oxygen, $\mathrm{O}_{2}$, to form a peroxy radical $\left(\mathrm{RO}_{2}\right)$. The subsequent reactions of those peroxy radicals have long been recognized as a key branching point in atmospheric photochemical mechanisms, ${ }^{7}$ and recently the complexity at the $\mathrm{RO}_{2}$ node has become even more interesting. Until recently, it was generally assumed that under atmospheric conditions unimolecular or bimolecular termination reactions inevitably prevented the addition of more than 4 oxygen atoms to a carbon backbone of an organic radical during one "generation" of chemistry from a stable molecular precursor to a stable molecular product. ${ }^{8}$ In order for large VOC molecules (such as biogenic monoterpenes with 10 carbon atoms) to be extensively oxidized, multiple reactions with low-concentration oxidants would therefore be required, making the process slow (taking hours or days). 
Recent experimental $1^{9,10,11,12,13,14,15,16}$ and theoretical ${ }^{9,11,17,18}$ research has demonstrated that for suitable VOC - oxidant combinations, a process called autoxidation can lead to very rapid (second-timescale) formation of highly oxidized molecules (denoted "HOM") after just a single initial reaction with an oxidant. Key to this autoxidation mechanism is a chain of sequential unimolecular peroxy radical hydrogen shifts (H-shifts) and $\mathrm{O}_{2}$ additions within peroxy radicals, eventually followed by either unimolecular or bimolecular termination reactions. The total molar yields of HOMs are relatively small, between a few and ten percent, ${ }^{11,13}$ but they may have an outsized influence on aerosol formation. Due to their high O:C ratios and multitude of hydrogenbonding functional groups, the HOMs formed by autoxidation have been assumed to be ELVOCs, implying ${ }^{19}$ saturation vapor pressures around or below about $10^{-14}$ bar for compounds with molar masses of a few hundred atomic mass units. It is important to note that while compounds with saturation vapor pressures in the LVOC regime, roughly $10^{-10 \ldots-14}$ bar, have negligible evaporation rates from bulk solutions or large aerosol particles, their evaporation from nanometer-sized aerosol particles is significant due to the Kelvin effect. Thus, saturation vapor pressures that are too low to measure by many experimental methods may still be too high to allow homogeneous nucleation, or even effective contributions to nanoparticle growth. ${ }^{20}$ The difference between LVOC and ELVOC is thus crucial for the smallest particle sizes, as the former evaporate from nanoparticles while the latter do not.

Much of the research on HOM/ELVOC formation has focused on ozone-initiated oxidation, either of model compounds such as simple cyclic alkenes like cyclohexene, or of the more complex but also more atmospherically relevant $\alpha$-pinene, one of the main monoterpenes emitted by vegetation, and a crucial SOA precursor. $\mathrm{OH}$-initiated autoxidation of $\alpha$-pinene has recently also been shown to produce significant amounts of HOM - compounds (unpublished results). 
The HOMs formed through both $\mathrm{O}_{3}$ - and $\mathrm{OH}$-initiated peroxy radical autoxidation represent a new and hitherto unknown class of compounds in the atmosphere. HOMs formed from the ozonolysis of endocyclic alkenes likely contain one or two peroxyacid $(\mathrm{C}(\mathrm{O}) \mathrm{OOH})$ functionalities, together with additional ketone $(\mathrm{C}=\mathrm{O})$, hydroperoxide $(\mathrm{C}-\mathrm{OOH})$ and possibly also alcohol $(\mathrm{C}-\mathrm{OH})$ or carboxylic acid $(\mathrm{C}(\mathrm{O}) \mathrm{OH})$ groups. ${ }^{12}$ In addition, reactions with $\mathrm{NO}_{\mathrm{X}}$ or $\mathrm{NO}_{3}$ may produce nitrate functional groups. Experimental observations, including the fact that these molecules are detected in the first place, indicate that HOMs have gas-phase lifetimes long enough to permit condensation (defined here as the uptake of gas molecules into a liquid phase of any composition). Even the $\mathrm{RO}_{2}$ radical intermediates of the autoxidation process likely have lifetimes on the order of seconds or more, and might thus possibly participate in, or initiate, condensed-phase reactions. ${ }^{13}$ HOMs may therefore affect aerosol properties and growth, and contribute to SOA formation. However, the subsequent condensed-phase reactions of these highly functionalized polyperoxides are probably rapid, and likely include both decomposition reactions (which increase volatility), oligomerization reactions (which decrease volatility), and photolysis (which leads to new highly reactive intermediates). Due to this high reactivity, HOMtype compounds are difficult, dangerous and potentially even impossible to synthesize in pure form. The industrial chemicals most closely related to the proposed HOMs are polyperoxides such as triacetone triperoxide, TATP - a well-known and notoriously hazardous high explosive. The lack of easily available pure compound samples presents severe challenges both for calibration of HOM detection methods, and for experimentally obtaining reliable estimates of their crucial properties such as saturation vapor pressures. 
Predicting the equilibrium phase partitioning of specific organic compounds requires accurate knowledge of their saturation vapor pressures as well as activity coefficients within the complex amorphous condensed phase comprising atmospheric organic particulate matter. A challenge is that the condensed-phase composition is poorly constrained. Simple bulk properties of the condensed phase such as the oxygen to carbon ratio $(\mathrm{O}: \mathrm{C})$ or the effective oxidation state of carbon $(\mathrm{OSc}=2 \mathrm{O}: \mathrm{C}-\mathrm{H}: \mathrm{C})$ are generally known, ${ }^{21}$ but even a single $100 \mathrm{~nm}$ particle may contain 1 million organic molecules, and in all probability more than 100,000 individual organic compounds, most of which have not been synthesized yet. ${ }^{19,21}$ The working hypothesis of highly simplified frameworks for atmospheric chemistry is that, on average, the complex distribution of functional groups within the organic condensed phase will result in equilibrium phase partitioning that is highly correlated first and foremost with the saturation vapor pressure.

Reliable information on the saturation vapor pressures of HOMs is thus a crucial precondition for determining their further reaction pathways, ultimate fate, and health and climate impact. While the large number of hydrogen-bonding functional groups of HOMs has been assumed to lead to low saturation vapor pressures, reliable data on their volatilities and solubilities do not exist. Quantum chemical calculations ${ }^{22}$ on clusters containing HOM-candidates from cyclohexene ozonolysis (e.g. a $\mathrm{C}_{6} \mathrm{H}_{8} \mathrm{O}_{7}$ ketodiperoxoic acid) show that their cluster-forming ability is much lower than expected, indicating (though not proving or quantifying) a surprisingly high volatility. Unfortunately, the basis datasets of existing group-contribution-based empirical parameterizations for determining saturation vapor pressures of organic molecules (e.g. SIMPOL $^{23}$, or the widely used and generally successful Nannoolal et al. approach ${ }^{24}$ ) do not contain complex polyhydroperoxides (or multiply substituted peroxy acids), and the parameterizations may therefore not be reliable for HOMs. While Compernolle et al. ${ }^{25,26}$ have 
extended the Nannoolal method to include hydroperoxides and peroxy acids, their dataset includes only monofunctional molecules of these types, and they indeed explicitly caution ${ }^{25}$ that the missing group-interaction parameters "can be especially important for the hydrogen-bonding hydroperoxide and peracid groups". The EVAPORATION method developed by Compernolle et $a l .{ }^{26}$ does include a limited number of peroxides and peroxy acids in its parameterization dataset, but the errors of the predicted saturation vapor pressures are the largest precisely for these particular groups of compounds. In a recent intercomparison, O'Meara et $a l^{27}$ found that the EVAPORATION method provided the most reliable saturation vapor pressures for the compounds to which it was applicable, with Nannoolal ${ }^{24}$ providing the lowest mean bias error for a larger set of compounds. However, EVAPORATION had a tendency to "increasingly underestimate vapour pressure with decreasing vapour pressure". According to Valorso et al. ${ }^{28}$, this is a common feature of group-contribution methods: all the methods in their comparison were found to underestimate the saturation vapor pressure of the multifunctional semivolatile species. Valorso et al. also found differences of several orders of magnitude in the saturation vapor pressures estimated by three different group-contribution approaches (including $\mathrm{Nannoolal}^{24}$ ) for low-volatility products of $\alpha$-pinene OH-oxidation including up to four different functional groups.

In this study, we use the COSMO-RS (COnductor-like Screening MOdel for Real Solvents) method, ${ }^{29,30}$ as implemented in the Turbomole ${ }^{31,32}$ and COSMOTherm programs ${ }^{33}$, to evaluate the (subcooled) liquid saturation vapor pressures of HOM candidate structures from $\alpha$-pinene ozonolysis, based on quantum chemical calculations, thus avoiding the need for system-specific empirical fitting parameters. COSMOTherm has previously been successfully applied to predict 
equilibrium gas-particle partitioning coefficients for alkane oxidation products relevant to SOA formation. $^{34}$

Within the COSMO-RS framework, saturation vapor pressures are computed as follows. First, quantum chemical calculations are performed on the molecule of interest both in "vacuum" (to obtain the reference gas-phase energy) and using COSMO, which is a type of continuum solvent model (CSM). ${ }^{35}$ The COSMO - calculation yields the screening charge surface (known as the $\sigma$ surface) of the molecule, which is converted into a distribution function (known as the $\sigma$-profile) giving the relative amount of the molecule's surface with a certain polarity. We show an illustrative $\sigma$-surface and $\sigma$-profile for the lowest-energy conformer of one of the molecules studied in this work in Figure 1. The intermolecular electrostatic, hydrogen bonding and van der Waals interactions between surface segments with different $\sigma$ values (polarities) can then be computed using various parameterizations. These are specific to the quantum-chemical method but not to the actual chemical system - though the numerical values of the parameters are obtained by fitting to large sets of experimental data. Multiple molecular conformations for each chemical may need to be included if they have significantly different polarities and/or hydrogen bonding patterns, and thus different $\sigma$-profiles. Once the molecular interactions are described, the chemical potential can be computed, and together with the gas-phase energy, the saturation vapor pressure can be obtained. For multicomponent mixtures, an additional parameterized combinatorial term is required, but this is not relevant for the pure-compound saturation vapor pressures we consider here. 


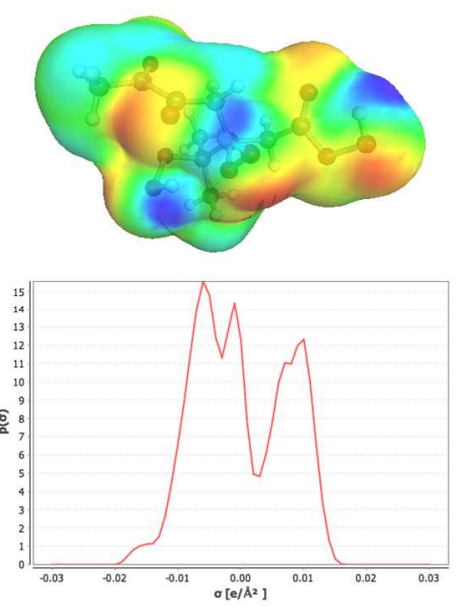

Figure 1. Top: screening charge surface ( $\sigma$-surface) for the lowest-energy conformer of the $\mathrm{C}_{10} \mathrm{H}_{16} \mathrm{O}_{9}$ molecule investigated in this study. Red regions indicate positive charge density, blue areas negative charge density. Hydrogen-bonding polar functional groups are clearly visible in the $\sigma$-surface. Bottom: the $\sigma$-profile computed from this surface, showing the relative amount of molecular surface with a certain polarity.

For compounds resembling those in the parameterization dataset of group-contribution methods, the absolute saturation vapor pressures predicted by COSMO-RS are likely somewhat less reliable than those predicted by those group-contribution methods. However, for compounds very different from the parameterization datasets, the COSMO-RS approach is more reliable, as it contains no system-specific parameters, and represents (albeit imperfectly and approximately) all of the chemical interactions present in the real chemical system.

\section{Computational Methods}

We conducted initial conformational sampling for the HOM-candidate molecules using the Spartan 14 program ${ }^{36}$, following the approach described in Rissanen et al. ${ }^{11}$ First, we performed systematic conformer sampling (for the monomers, i.e. the autoxidation products with 10 carbon 
atoms) or Monte-Carlo sampling (for the dimers, i.e. the autoxidation products with 20 carbon atoms) using the MMFF force-field, in order to produce a representative set of unique conformers. Next, we computed the B3LYP/6-31+G(d) single-point energy of these structures. We then performed B3LYP/6-31+G(d) optimizations on up to 100 structures with B3LYP/6$31+\mathrm{G}(\mathrm{d})$ single-point energies within $5 \mathrm{kcal} / \mathrm{mol}$ of the lowest-energy conformer. All MMFF and B3LYP calculations were performed on Spartan '14.

We selected the best 20 of the optimized structures for each HOM candidate (based on the energy of the B3LYP-optimized structure) for COSMO-RS calculations using Turbomole version $6.6^{31}$, followed by saturation vapor pressure calculations using COSMOTherm (version 15.0.2) $)^{33}$. We visually inspected the structures to ensure that we included conformers with different hydrogen-bonding patterns in the saturation vapor pressure calculations (though the very large number of conformers especially for the larger HOM-candidates prevented a complete selection of all possible potential H-bonding patterns). We carried out comprehensive test calculations, which indicated that the saturation vapor pressure values were essentially converged with respect to the number of conformers once we included 10-20 of the lowestenergy conformers. We also tested the effect of including higher-energy conformers lacking, or having a smaller number of, internal H-bonds (which could potentially be more stable in the liquid phase due to increased capacity for intermolecular hydrogen bonding, and thus contribute to the saturation vapor pressures despite higher gas-phase energies). These tests indicated that the effect of such conformers on the saturation vapor pressure was negligible. For the test-set molecules (see below), we first generated the full list of conformers using Spartan '14 as described above. We then manually arranged conformers into groups with distinctly different hydrogen bonding patterns and dipole moments, and we selected the lowest-energy conformer 
from each group (for a maximum of five groups per molecule) for the saturation vapor pressure calculations. As discussed in the COSMOTherm documentation ${ }^{37}$, alkyl group conformational differences do not significantly affect saturation vapor pressures, so this approach is likely to give a reasonable picture of the effect of including multiple conformers on the predicted saturation vapor pressure.

We performed the COSMOTherm/Turbomole calculations using the default settings recommended by the program manuals. We first performed gas-phase and COSMO calculations using Turbomole, either at the BP/TZVP level or the BP/TZVPD-FINE level. These yielded the .cosmo input files for subsequent COSMOTherm saturation vapor pressure calculations (See the Supporting Information for the .cosmo input files for all studied HOM-candidate species). Here, "BP/TZVP" refers to a RI-DFT calculation using the B88-VWN-P86 functional, the TZVP basis set $^{38}$ and the associated auxiliary basis set for the RI expansion, and the default settings for the COSMO cavity construction. Similarly, "BP/TZVPD-FINE" refers to a RI-DFT single-point energy calculation on top of the BP/TZVP geometry, performed using the same density functional but the larger TZVPD basis set (and associated auxiliary basis set), and using a finer grid for the surface cavity construction in the COSMO calculations. The parameter set for the COSMOTherm chemical potential calculations using the BP/TZVPD-FINE $\sigma$-profiles contains additional terms for hydrogen bonding and van der Waals dispersion, and according to the COSMOTherm documentation often improves accuracy for systems where the default BP/TZVP approach performs poorly. ${ }^{39}$ Due to the computational expense (caused primarily by the lack of parallelized versions of some of the Turbomole modules required for the BP/TZVPD-FINE calculations), we only computed the BP/TZVPD-FINE vapor pressures for the test-set molecules and the "HOM dimers" (with 20 carbon atoms) for the lowest-energy conformer of each studied 
system. We note that due (presumably) to small differences in the implementation of the BP/TZVPD-FINE parameterization of COSMO-RS in different Turbomole versions (e.g. 6.6 vs 7.0), the BP/TZVPD-FINE saturation vapor pressures predicted (for identical molecular structures, using the same version of COSMOTherm) may differ by some tens of percent depending on the Turbomole version used to generate the .cosmo files. All saturation vapor pressures in this study are computed using .cosmo files generated by the same version (Turbomole v 6.6.) and are therefore intercomparable.

We evaluated the Nannoolal et al. $^{24}$ and EVAPORATION ${ }^{26}$ group-contribution saturation vapor pressures using the UManSysProp online system ${ }^{40}$, in the former case using the Nannoolal et $a .^{41}$ boiling point parameterization, as recommended e.g. by O'Meara et al. ${ }^{27}$ The EVAPORATION method does not require a boiling point parameterization (despite the requirement to select one in the UManSysProp input). We note that using Nannoolal et al. ${ }^{24}$ together with the older boiling point parameterizations available in UManSysProp led to very different (and physically unreasonably low, e.g. $10^{-32}$ bar) saturation vapor pressure values for some of the HOM candidates. We generated the SMILES - strings required by UManSysProp from the xyz co-ordinate files produced by Spartan using the OpenBabel conversion program ${ }^{42}$ in order to eliminate errors from incorrect structure assignments (the Spartan program produced incorrect SMILES strings for some of the peroxide compounds in this study).

We derived the SIMPOL saturation vapor pressures using chemical group-contribution parameters from Pankow and Asher. ${ }^{23}$ The SIMPOL method is based on nonlinear regression least-square fitting to measured saturation vapor pressures of 272 organic compounds, with saturation vapor pressures spanning 14 orders of magnitude. Only seven of these compounds contain hydroperoxide- or peroxyacid functional groups. In total SIMPOL considers 30 first- or 
second-order chemical groups of which the number of carbon atoms, non-aromatic rings (second-order), hydroxyl-, aldehyde-, ketone-, carboxylic acid-, peroxide-, hydroperoxide- and carbonylperoxyacid groups are relevant for the 16 HOMs candidate structures considered in this work.

\section{Results and discussion}

\section{Testing COSMOTherm saturation vapor pressure predictions for atmospherically} relevant molecules

The performance of COSMO-RS/COSMOTherm has been extensively validated for several liquid-phase thermodynamic parameters such as partition coefficients, activity coefficients and solvation free energies (see e.g. Klamt ${ }^{43}$ for a review). Absolute saturation vapor pressures (in the absence of experimental data) are unfortunately not the main focus on COSMORS theory development, and systematic benchmarking or validation studies on the accuracy of COSMOTherm - computed saturation vapor pressures are therefore scarce. According to Eckert and $\mathrm{Klamt}^{30}$, the maximum deviation for the saturation vapor pressure predicted for the parameterization dataset of 310 compounds is a factor of 3.7. However, the accuracy of the saturation vapor pressure predictions, unlike the activity coefficient, Henry's law coefficient and excess free energy predictions, are not subsequently evaluated on a larger test-set, making the quantitative assessment of error margins difficult. In a MSc thesis work, A. Gasawi ${ }^{44}$ found that for a test-set of 71 pure compounds, the COSMOTherm saturation vapor pressures between 300 and $500 \mathrm{~K}$ were between $3 \%$ and $142 \%$ of the experimental values. The accuracy of saturation vapor pressure predictions can also be estimated from the accuracy of the COSMOTherm solvation free energies, which are generally ${ }^{45}$ better than $1 \mathrm{kcal} / \mathrm{mol}$ for the standard BP/TZVP 
parameterization - implying that the saturation vapor pressure is accurate to about a factor of 5 or better (though with significantly larger errors possible for some outliers, as indicated already by the work of Gasawi $^{44}$ ). The BP/TZVPD-FINE saturation vapor pressure predictions have recently been tested on an extremely large saturation vapor pressure dataset of 21607 data points $^{46}$ (including some of the molecules of the parameterization dataset), with a RMS deviation of a factor of 1.5 and a maximum deviation of a factor of 50 (private communications, Dr. Jens Reinisch).

Before computing the saturation vapor pressures of HOM candidate structures, we used COSMOTherm to compute the saturation vapor pressures for a small set of atmospherically relevant organic compounds with $\mathrm{O}: \mathrm{C}$ ratios ranging from 0 to 0.8 , for which experimental saturation vapor pressures are known. These molecules were fluoranthene, 4-tert-butylcatechol, adipic acid, pimelic acid and levoglucosan (see Figure S1 in the Supporting Information for molecular structures). In addition to confirming the order-of-magnitude applicability of the COSMOTherm approach to atmospherically relevant systems, the purpose of these calculations was to test whether or not there is a systematic trend in the errors of the predicted saturation vapor pressure with respect to the oxidation state of the molecules. We also calculated the saturation vapor pressures of peroxyformic and peroxyacetic acid in order to assess the performance of COSMOTherm for the peroxy acids formed by autoxidation.

The results, presented in Table 1, are more or less in line with literature benchmarking studies. While far from quantitative, the COSMOTherm saturation vapor pressure predictions are within a factor of 50 of the measured values. This is roughly comparable to the performance of the group-contribution methods, which are within a factor of 20 of the experimental values for most of the molecules (pimelic acid, adipic acid, levoglucosan, peroxyacetic acid; see Table S1 in the 
Supporting Information). The worst mismatch between SIMPOL ${ }^{23}$ and experimental data was a factor of 72, comparable to the performance of COSMOTherm. On the other hand, the other two group-contribution methods had much more extreme outliers than COSMOTherm, namely an overestimation of the saturation vapor pressure of fluoranthene by a factor of 6600 by Nannoolal $^{24} /$ Nannoolal $^{41}$, and an overestimation of the saturation vapor pressure of 4tertbutylcatechol by a factor of $3.8 \times 10^{6}$ by EVAPORATION. ${ }^{26}$ These large outliers may be illustrative of the danger of using group-contribution methods for chemical compounds far from their parameterization dataset. For example, the EVAPORATION method is not parameterized for aromatic compounds, ${ }^{27}$ so the poor performance for 4-tertbutylcatechol should not be surprising. See the Supporting Information (Table S1) for saturation vapor pressures computed with the three group-contribution methods used in this study for the molecules in Table 1.

In contrast to the test-set of Gasawi ${ }^{44}$, where the largest overprediction by COSMOTherm was less than a factor of 1.5, overprediction was both more frequent and more extreme than underprediction for our limited test-set: the only molecule for which the saturation vapor pressure was underpredicted was 4-tert-butylcatechol. Apart from this, we could discern no systematic trends in the size or direction of the error, for example with respect to the O:C ratio. The saturation vapor pressure of peroxyacetic acid is overestimated by about an order of magnitude by all the COSMOTherm approaches. We were unable to find a genuine experimental value for the saturation vapor pressure of peroxyformic acid; e.g. the value quoted in the PubChem database turned out to be a modeled estimate rather than an experimental result.

Including multiple conformers in the calculations always decreased the saturation vapor pressures for this dataset, but by less than an order of magnitude. This improved the agreement with experiments for all molecules except 4-tert-butylcatechol: however, for this molecule the 
difference between single- and multiconformer results was also very small, as it has little conformational flexibility. Using the BP/TZVPD-FINE parameterization instead of the standard BP/TZVP parameterization for a single conformer could either increase or decrease the predicted saturation vapor pressure, but again by less than an order of magnitude. Using the BP/TZVPDFINE parameterization for a single conformer did not systematically reduce the error of the predicted saturation vapor pressures (in the sense of always decreasing the difference between the predicted and measured values). This indicates that for a rough order-of-magnitude estimate of the saturation vapor pressure, a BP/TZVP calculation on a single low-energy conformer may be sufficient and cost-effective, though including multiple conformers is likely to improve the accuracy of the result. Also, we tentatively conclude that the COSMOTherm - predicted saturation vapor pressures for the molecules in this study are more likely to be too high than too low - in contrast to the group-contribution methods. ${ }^{28}$

Table 1. Modeled and measured saturation vapor pressures for a set of test compounds (all values in bar, and at $298.15 \mathrm{~K}$ ).

\begin{tabular}{|l|l|l|l|l|l|}
\hline molecule & $\begin{array}{l}\mathrm{p}_{\text {sat single }} \\
\text { conformer, } \\
\text { BP/TZVP }\end{array}$ & $\begin{array}{l}\mathrm{p}_{\text {sat multiple }} \text { conformers, } \\
\text { BP/TZVP }\end{array}$ & $\begin{array}{l}\mathrm{p}_{\text {sat, single }} \\
\text { conformer, } \\
\text { BP/TZVPD- } \\
\text { FINE }\end{array}$ & Experimental & Reference \\
\hline Fluoranthene & $5.4 \times 10^{-7}$ & $5.4 \times 10^{-7}$ & $4.9 \times 10^{-7}$ & $1.2 \times 10^{-8}$ & 47 \\
\hline 4-t.butylcatechol & $1.5 \times 10^{-6}$ & $1.4 \times 10^{-6}$ & $3.4 \times 10^{-6}$ & $3.7 \times 10^{-6}$ & 48 \\
\hline Pimelic acid & $5.0 \times 10^{-8}$ & $2.0 \times 10^{-8}$ & $2.2 \times 10^{-8}$ & $2.7 \times 10^{-9}$ & 49 \\
\hline Adipic acid & $6.9 \times 10^{-8}$ & $3.6 \times 10^{-8}$ & $3.6 \times 10^{-8}$ & $2.1 \times 10^{-9}$ & 49 \\
\hline Levoglucosan & $1.6 \times 10^{-8}$ & $8.5 \times 10^{-9}$ & $9.5 \times 10^{-8}$ & $1.9 \times 10^{-9}$ & 49 \\
\hline
\end{tabular}




\begin{tabular}{|l|l|l|l|l|l|}
\hline $\begin{array}{l}\text { Peroxyformic } \\
\text { acid }\end{array}$ & $6.0 \times 10^{-1}$ & $4.9 \times 10^{-1}$ & $1.1 \times 10^{0}$ & - & - \\
\hline $\begin{array}{l}\text { Peroxyacetic } \\
\text { acid }\end{array}$ & $1.3 \times 10^{-1}$ & $1.2 \times 10^{-1}$ & $2.3 \times 10^{-1}$ & $1.9 \times 10^{-2}$ & 50 \\
\hline
\end{tabular}

\section{Selecting HOM candidate structures}

For this study, we have selected 16 different potential HOM autoxidation products, all of which could possibly be formed in the $\mathrm{O}_{3}$-initiated autoxidation of $\alpha$-pinene. The precise reaction pathway of this process is as yet unknown. High-resolution mass spectrometric measurements, combined with e.g. H/D exchange experiments, yield the elemental composition and the number of acidic $(\mathrm{OH}$ or $\mathrm{OOH})$ hydrogen atoms in the autoxidation products, but no other information on their actual molecular structures. High-level quantum chemical calculations ${ }^{51}$ on the H-shifts of the first-generation $\mathrm{RO}_{2}$ radicals formed in $\alpha$-pinene ozonolysis (with the elemental composition $\mathrm{C}_{10} \mathrm{H}_{15} \mathrm{O}_{4}$ ) strongly indicate that in order to add more than 4-5 oxygen atoms to the carbon backbone through autoxidation, the cyclobutyl ring left intact by the ozonolysis reaction must be broken, either by bimolecular reactions forming alkoxy radicals (which subsequently undergo prompt ring-breaking), or via more speculative unimolecular channels. Ring-breaking reactions inevitably increase the conformational flexibility of the carbon backbone significantly, and allow for H-shifts from several different sites, including not only the aldehydic groups, but also tertiary carbon atoms and carbon atoms adjacent to ketone groups, which are known to enhance H-shift rates. $^{52}$ 
Once $\mathrm{RO}_{2}$ radicals with at least one $\mathrm{OOH}$ group are formed, ultra-fast COO...H...OOC hydrogen shifts ${ }^{53}$ very likely "scramble" the position of the radical group, further increasing the number of possible structures and reaction paths. Bimolecular reactions (with e.g. $\mathrm{HO}_{2}, \mathrm{NO}$ or other $\mathrm{RO}_{2}$ ) can either propagate the reaction chain through alkoxy radical formation, or terminate it through several possible channels (including "dimer" formation, possibly through direct or indirect reactions of the type $\mathrm{RO}_{2}+\mathrm{RO}_{2} \Rightarrow \mathrm{ROOR}+\mathrm{O}_{2}$ ). Unimolecular termination reactions via $\mathrm{OH}$ loss are also possible, mainly after H-shifts from carbon atoms with hydroperoxy groups.

This multitude of reactions and reaction pathways means that, despite the combined experimental and theoretical constraints, there are hundreds of possible HOM structures in the $\alpha$ pinene $+\mathrm{O}_{3}$ system alone. In this study, we have attempted to model a representative sample of these possible structures, shown in Figure 2 (with three-dimensional structures of the lowestenergy conformers shown in Figure 3). The set of HOM-candidate structures included in the study are not intended to correspond only to the "most probable" HOM structures (which, based on our current limited mechanistic understanding, contain mainly ketone, hydroperoxy and peroxy acid functional groups), but also to include chemically more diverse functionalities, including also alcohol, carboxylic acid and endoperoxy (C-O-O-C) groups. The formation of some of the studied HOM-candidate structures thus requires fairly speculative reaction mechanisms, such as ring-opening via Criegee Intermediates, ${ }^{54}$ or peroxy radical ring closure to

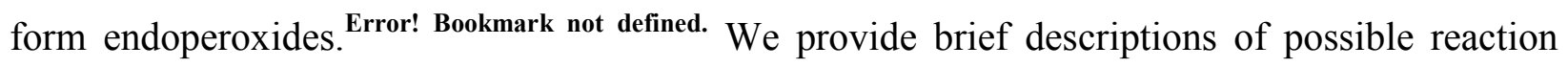
paths leading to all 16 studied compounds in the Supporting Information. 


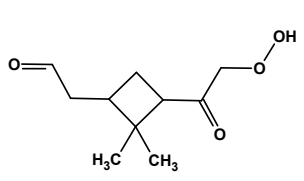

a

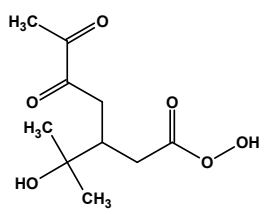

e

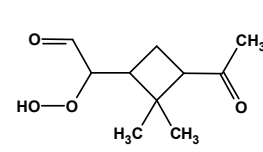

b

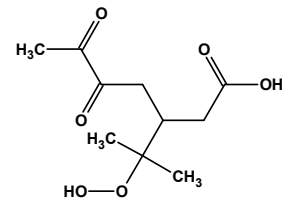

f

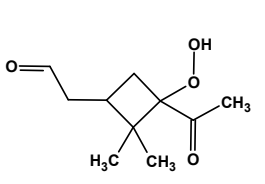

c

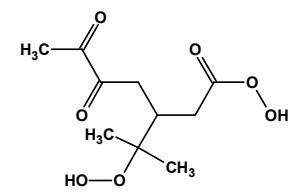

g

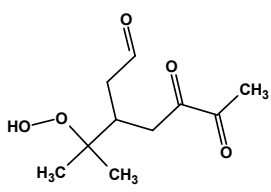

d

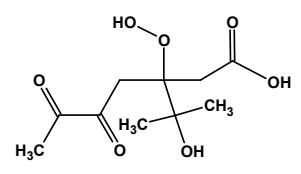

h

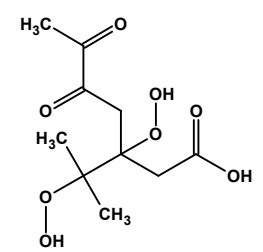

i

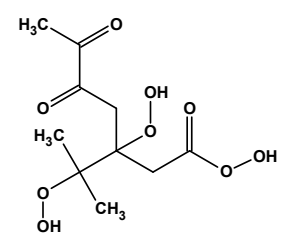

I

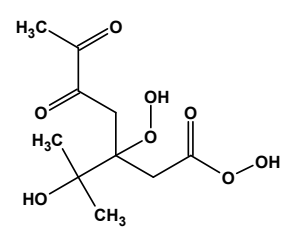

j

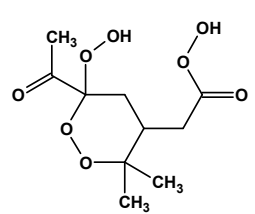

k 

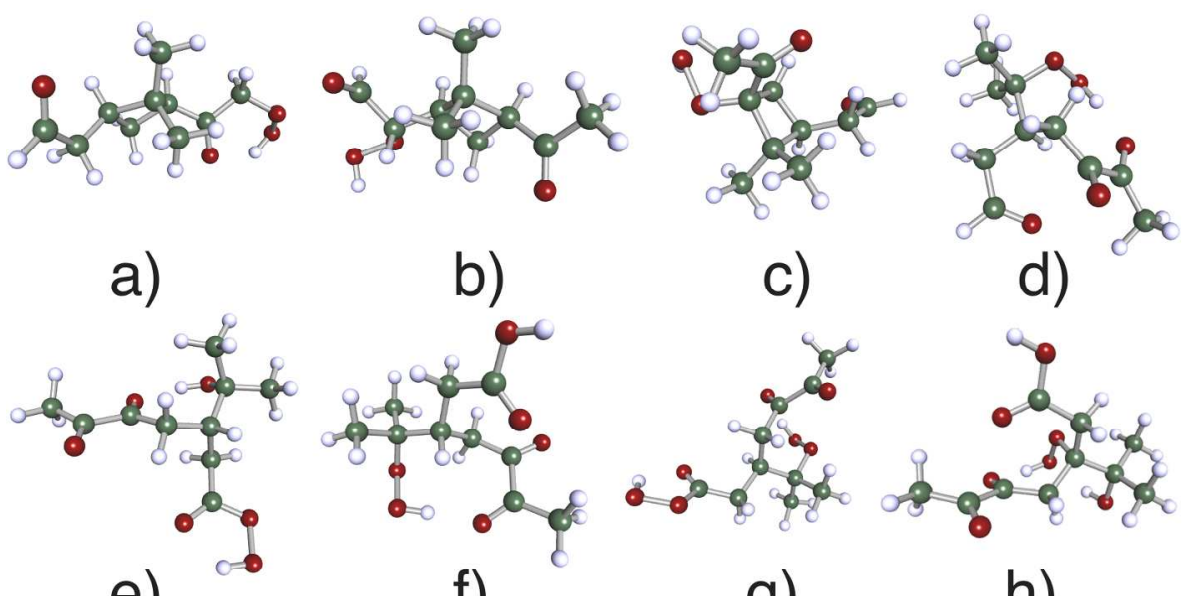

e)

f)

g)

h)

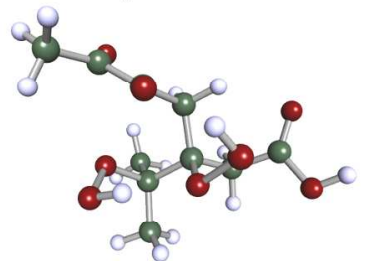

i)

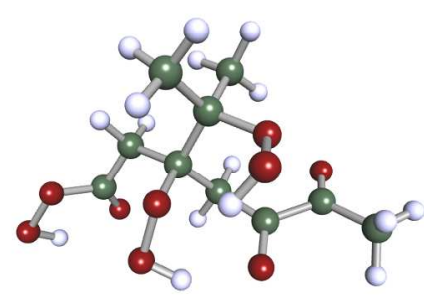

l)

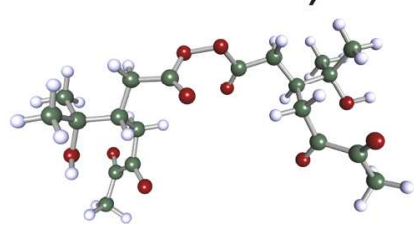

n)

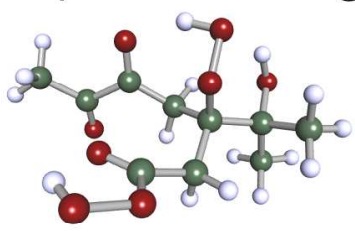

j)
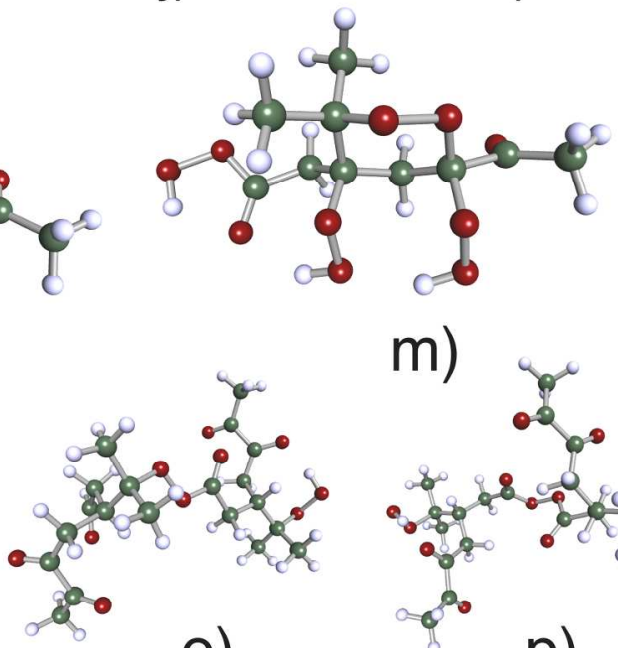

0) m)

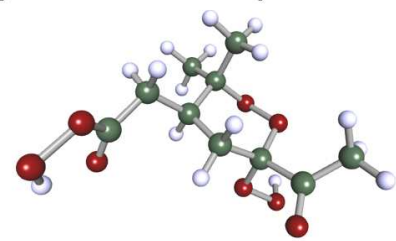

k)

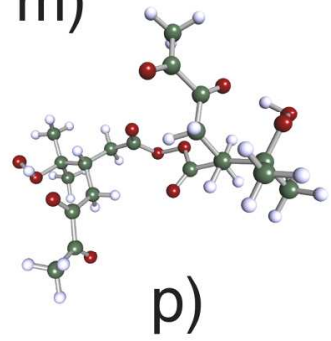

Figure 3. Lowest-energy conformers of the HOM-candidate structures shown in Figure 2, at the BP/TZVP level with COSMO-RS. Color coding: green=carbon, red=oxygen, white=hydrogen.
a) $\mathrm{C}_{10} \mathrm{H}_{16} \mathrm{O}_{4}$-isol,
b) $\mathrm{C}_{10} \mathrm{H}_{16} \mathrm{O}_{4}$-iso2,
c) $\mathrm{C}_{10} \mathrm{H}_{16} \mathrm{O}_{4}$-iso3,
d) $\mathrm{C}_{10} \mathrm{H}_{16} \mathrm{O}_{5}$,
e) $\mathrm{C}_{10} \mathrm{H}_{16} \mathrm{O}_{6}$-isol,

f) $\mathrm{C}_{10} \mathrm{H}_{16} \mathrm{O}_{6}$-iso2, g) $\mathrm{C}_{10} \mathrm{H}_{16} \mathrm{O}_{7}$-iso1, h) $\mathrm{C}_{10} \mathrm{H}_{16} \mathrm{O}_{7}$-iso2, i) $\mathrm{C}_{10} \mathrm{H}_{16} \mathrm{O}_{8}$-iso1, j) $\mathrm{C}_{10} \mathrm{H}_{16} \mathrm{O}_{8}$-iso2, k) $\mathrm{C}_{10} \mathrm{H}_{16} \mathrm{O}_{8}$-iso3, l) $\left.\left.\mathrm{C}_{10} \mathrm{H}_{16} \mathrm{O}_{9}, \mathrm{~m}\right) \mathrm{C}_{10} \mathrm{H}_{16} \mathrm{O}_{10}, \mathrm{n}\right) \mathrm{C}_{20} \mathrm{H}_{30} \mathrm{O}_{10}$-iso1, o) $\mathrm{C}_{20} \mathrm{H}_{30} \mathrm{O}_{10}$-iso2, p) $\mathrm{C}_{20} \mathrm{H}_{30} \mathrm{O}_{12}$. 


\section{Saturation vapor pressures of HOM candidates}

The saturation vapor pressures of the HOM candidates computed using COSMOTherm are given in Table 2. For comparison, we give values computed using the Nannoolal et al., ${ }^{24}$ EVAPORATION $^{26}$ and SIMPOL ${ }^{23}$ group-contribution based parameterizations in Table 3.

Table 2. Saturation vapor pressures (in bar) at 298.15 K for HOM-candidate structures, using COSMOTherm and the BP/TZVP or BP/TZVPD-FINE parameterizations for COSMO-RS, and either one or 20 conformers. $^{\text {a }}$

\begin{tabular}{|l|l|l|l|l|}
\hline Molecule & $\begin{array}{l}p_{\text {sat, }} \text { conformer } \\
\text { BP/TZVP }\end{array}$ & $\begin{array}{l}p_{\text {sat multiple }} \\
\text { conformers, } \\
\text { BP/TZVP }\end{array}$ & $\begin{array}{l}p_{\text {sat, single }} \\
\text { conformer BP/ } \\
\text { TZVPD-FINE }\end{array}$ & $\begin{array}{l}p_{\text {sat, multiple }} \\
\text { conformersBP/ } \\
\text { TZVPD- FINE }\end{array}$ \\
\hline $\mathrm{C}_{10} \mathrm{H}_{16} \mathrm{O}_{4}$-iso1 & $2.6 \times 10^{-7}$ & $1.1 \times 10^{-7}$ & $1.1 \times 10^{-6}$ & $5.2 \times 10^{-7}$ \\
\hline $\mathrm{C}_{10} \mathrm{H}_{16} \mathrm{O}_{4}$-iso2 & $2.4 \times 10^{-8}$ & $6.3 \times 10^{-8}$ & $4.7 \times 10^{-8}$ & $1.5 \times 10^{-7}$ \\
\hline $\mathrm{C}_{10} \mathrm{H}_{16} \mathrm{O}_{4}$-iso3 & $1.6 \times 10^{-7}$ & $1.7 \times 10^{-7}$ & $2.2 \times 10^{-7}$ & $2.1 \times 10^{-7}$ \\
\hline $\mathrm{C}_{10} \mathrm{H}_{16} \mathrm{O}_{5}$ & $8.0 \times 10^{-7}$ & $6.0 \times 10^{-7}$ & $1.0 \times 10^{-6}$ & $8.5 \times 10^{-7}$ \\
\hline $\mathrm{C}_{10} \mathrm{H}_{16} \mathrm{O}_{6}$-iso1 & $6.4 \times 10^{-7}$ & $8.7 \times 10^{-8}$ & $3.5 \times 10^{-6}$ & $3.6 \times 10^{-7}$ \\
\hline $\mathrm{C}_{10} \mathrm{H}_{16} \mathrm{O}_{6}$-iso2 & $1.3 \times 10^{-8}$ & $1.1 \times 10^{-8}$ & $8.3 \times 10^{-9}$ & $9.3 \times 10^{-9}$ \\
\hline $\mathrm{C}_{10} \mathrm{H}_{16} \mathrm{O}_{7}$-iso1 & $3.2 \times 10^{-7}$ & $1.7 \times 10^{-7}$ & $1.2 \times 10^{-6}$ & $7.0 \times 10^{-7}$ \\
\hline $\mathrm{C}_{10} \mathrm{H}_{16} \mathrm{O}_{7}$-iso2 & $2.8 \times 10^{-9}$ & $3.1 \times 10^{-9}$ & $1.5 \times 10^{-9}$ & $1.7 \times 10^{-9}$ \\
\hline $\mathrm{C}_{10} \mathrm{H}_{16} \mathrm{O}_{8}$-iso1 & $5.6 \times 10^{-9}$ & $2.4 \times 10^{-9}$ & $9.1 \times 10^{-9}$ & $9.4 \times 10^{-10}$ \\
\hline $\mathrm{C}_{10} \mathrm{H}_{16} \mathrm{O}_{8}$-iso2 & $1.0 \times 10^{-7}$ & $6.1 \times 10^{-8}$ & $4.1 \times 10^{-7}$ & $1.5 \times 10^{-7}$ \\
\hline $\mathrm{C}_{10} \mathrm{H}_{16} \mathrm{O}_{8}$-iso3 & $1.3 \times 10^{-9}$ & $1.9 \times 10^{-9}$ & $7.7 \times 10^{-9}$ & $1.2 \times 10^{-8}$ \\
\hline $\mathrm{C}_{10} \mathrm{H}_{16} \mathrm{O}_{9}$ & $4.3 \times 10^{-8}$ & $6.2 \times 10^{-8}$ & $2.4 \times 10^{-7}$ & $2.3 \times 10^{-7}$ \\
\hline $\mathrm{C}_{10} \mathrm{H}_{16} \mathrm{O}_{10}$ & $1.9 \times 10^{-9}$ & $1.6 \times 10^{-10}$ & $3.5 \times 10^{-8}$ & $1.7 \times 10^{-9}$ \\
\hline $\mathrm{C}_{20} \mathrm{H}_{30} \mathrm{O}_{10}$-iso1 & $3.2 \times 10^{-16}$ & $9.0 \times 10^{-15}$ & $1.3 \times 10^{-12}$ & - \\
\hline
\end{tabular}




\begin{tabular}{|l|l|l|l|l|}
\hline $\mathrm{C}_{20} \mathrm{H}_{30} \mathrm{O}_{10}$-iso2 & $1.0 \times 10^{-13}$ & $1.6 \times 10^{-12}$ & $5.7 \times 10^{-13}$ & - \\
\hline $\mathrm{C}_{20} \mathrm{H}_{30} \mathrm{O}_{12}$ & $9.4 \times 10^{-12}$ & $3.0 \times 10^{-12}$ & $7.1 \times 10^{-11}$ & - \\
\hline
\end{tabular}

a)Only ten unique conformers were found for the $\mathrm{C}_{10} \mathrm{H}_{16} \mathrm{O}_{4}$-iso3 structure.

Table 3. Saturation vapor pressures (in bar) at 298.15 K for HOM-candidate structures, using the Nannoolal et al. vapor pressure parameterization ${ }^{24}$ with the Nannoolal et al. boiling point parameterization $^{41}$ (Nannoolal/Nannoolal), the EVAPORATION parameterization ${ }^{26}$, or the SIMPOL $^{23}$ parameterization.

\begin{tabular}{|l|l|l|l|}
\hline Molecule & $\begin{array}{l}p_{\text {sat}}, \\
\text { Nannoolal/Nannoolal }\end{array}$ & $p_{\text {sat, EVAPORATION }}$ & $p_{\text {sat, SIMPOL }}$ \\
\hline $\mathrm{C}_{10} \mathrm{H}_{16} \mathrm{O}_{4}$-iso1 & $1.8 \times 10^{-6}$ & $9.5 \times 10^{-7}$ & $7.6 \times 10^{-8}$ \\
\hline $\mathrm{C}_{10} \mathrm{H}_{16} \mathrm{O}_{4}$-iso2 & $3.3 \times 10^{-6}$ & $1.5 \times 10^{-6}$ & $7.6 \times 10^{-8}$ \\
\hline $\mathrm{C}_{10} \mathrm{H}_{16} \mathrm{O}_{4}$-iso3 & $7.2 \times 10^{-7}$ & $7.5 \times 10^{-7}$ & $7.6 \times 10^{-8}$ \\
\hline $\mathrm{C}_{10} \mathrm{H}_{16} \mathrm{O}_{5}$ & $5.8 \times 10^{-8}$ & $1.8 \times 10^{-8}$ & $9.3 \times 10^{-9}$ \\
\hline $\mathrm{C}_{10} \mathrm{H}_{16} \mathrm{O}_{6}$-iso1 & $1.1 \times 10^{-8}$ & $1.1 \times 10^{-8}$ & $1.3 \times 10^{-9}$ \\
\hline $\mathrm{C}_{10} \mathrm{H}_{16} \mathrm{O}_{6}$-iso2 & $8.3 \times 10^{-11}$ & $3.4 \times 10^{-11}$ & $6.0 \times 10^{-11}$ \\
\hline $\mathrm{C}_{10} \mathrm{H}_{16} \mathrm{O}_{7}$-iso1 & $3.9 \times 10^{-10}$ & $3.2 \times 10^{-10}$ & $7.2 \times 10^{-10}$ \\
\hline $\mathrm{C}_{10} \mathrm{H}_{16} \mathrm{O}_{7}$-iso2 & $2.6 \times 10^{-14}$ & $1.1 \times 10^{-12}$ & $3.9 \times 10^{-13}$ \\
\hline $\mathrm{C}_{10} \mathrm{H}_{16} \mathrm{O}_{8}$-iso1 & $4.6 \times 10^{-16}$ & $2.2 \times 10^{-14}$ & $2.2 \times 10^{-13}$ \\
\hline $\mathrm{C}_{10} \mathrm{H}_{16} \mathrm{O}_{8}$-iso2 & $1.9 \times 10^{-13}$ & $1.1 \times 10^{-11}$ & $4.7 \times 10^{-12}$ \\
\hline $\mathrm{C}_{10} \mathrm{H}_{16} \mathrm{O}_{8}$-iso3 & $2.0 \times 10^{-9}$ & $6.7 \times 10^{-10}$ & $2.4 \times 10^{-9}$ \\
\hline $\mathrm{C}_{10} \mathrm{H}_{16} \mathrm{O}_{9}$ & $3.9 \times 10^{-15}$ & $2.2 \times 10^{-13}$ & $2.6 \times 10^{-12}$ \\
\hline $\mathrm{C}_{10} \mathrm{H}_{16} \mathrm{O}_{10}$ & $4.4 \times 10^{-14}$ & $1.8 \times 10^{-13}$ & $8.7 \times 10^{-12}$ \\
\hline $\mathrm{C}_{20} \mathrm{H}_{30} \mathrm{O}_{10}$-iso1 & $8.3 \times 10^{-10}$ & $2.1 \times 10^{-14}$ & $8.0 \times 10^{-16}$ \\
\hline $\mathrm{C}_{20} \mathrm{H}_{30} \mathrm{O}_{10}$-iso2 & $2.5 \times 10^{-11}$ & $1.4 \times 10^{-15}$ \\
\hline
\end{tabular}




\begin{tabular}{|l|l|l|l}
$\mathrm{C}_{20} \mathrm{H}_{30} \mathrm{O}_{12}$ & $2.3 \times 10^{-12}$ & $1.9 \times 10^{-17}$ & $2.9 \times 10^{-18}$
\end{tabular}

We used four levels of theory to compute the saturation vapor pressure with COSMOTherm: BP/TZVP $\sigma$-profiles for the single lowest-energy conformer; BP/TZVP $\sigma$ profiles for the 20 lowest-energy conformers; BP/TZVPD-FINE $\sigma$-profiles for the single lowestenergy conformer; or BP/TZVPD-FINE $\sigma$-profiles for the 20 lowest-energy conformers excluding the "dimers". The four sets of saturation vapor pressures computed by COSMOTherm are within a factor of 100 of each other for all cases except for $\mathrm{C}_{10} \mathrm{H}_{16} \mathrm{O}_{10}$ and $\mathrm{C}_{20} \mathrm{H}_{30} \mathrm{O}_{10}$-iso1, for which the ratio between the highest and lowest predicted saturation vapor pressures are around 200 and 4000, respectively. There is no clear systematic relation between the four sets of COSMOTherm predictions. Increasing the number of conformers can either increase or decrease the predicted saturation vapor pressures of the HOM-candidate molecules, with decreases being somewhat more frequent in the studied set $(9$ cases of lower and 7 cases of higher vapor pressures at the BP/TZVP level, and 9 cases of lower and 4 cases of higher vapor pressures at BP/TZVPD-FINE level). Using the BP/TZVPD-FINE parameterization instead of the default BP/TZVP parameterization usually increases the predicted saturation vapor pressures, but in a few cases we observe the opposite (14 cases of higher and 2 cases of lower vapor pressures for the single-conformer predictions, and 10 cases of higher and 3 cases of lower vapor pressures for the multi-conformer predictions). The two improvements to the BP/TZVP single-conformer predictions thus often act in opposite directions.

The three group-contribution methods mostly predict lower saturation vapor pressures than the four COSMOTherm - based approaches. The maximum difference between all three group-contribution predictions and any of the four COSMOTherm saturation vapor pressure 
datasets is 7-8 orders of magnitude. The largest differences are observed for the most highly oxidized monomers, and for the dimers. For the least oxidized monomers (the three $\mathrm{C}_{10} \mathrm{H}_{16} \mathrm{O}_{4}$ isomers), both Nannoolal/Nannoolal and EVAPORATION actually predict somewhat higher saturation vapor pressures than most of the COSMOTherm approaches, though all methods are in reasonable agreement for these species. The Nannoolal/Nannoolal method also predicts higher saturation vapor pressures for the dimers than most of the COSMOTherm approaches, in contrast to the trend observed for the more oxidized monomers.

The three group-contribution methods are within 3 orders of magnitude of each other for the monomers, but disagree by up to 8 orders of magnitude for the dimers (with the Nannoolal/Nannoolal and SIMPOL predictions of the saturation vapor pressure for $\mathrm{C}_{20} \mathrm{H}_{30} \mathrm{O}_{10^{-}}$ iso1 being $8.3 \times 10^{-10}$ bar and $9.5 \times 10^{-18}$ bar, respectively). Even the somewhat more sophisticated Nannoolal/Nannoolal and EVAPORATION methods disagree by 4-5 orders of magnitude for the dimer saturation vapor pressures.

To illustrate the spread in the saturation vapor pressure predictions of the different methods, Figure 4 shows the saturation vapor pressures predicted by two of the COSMOTherm approaches and the EVAPORATION method, plotted against the SIMPOL saturation vapor pressures. 


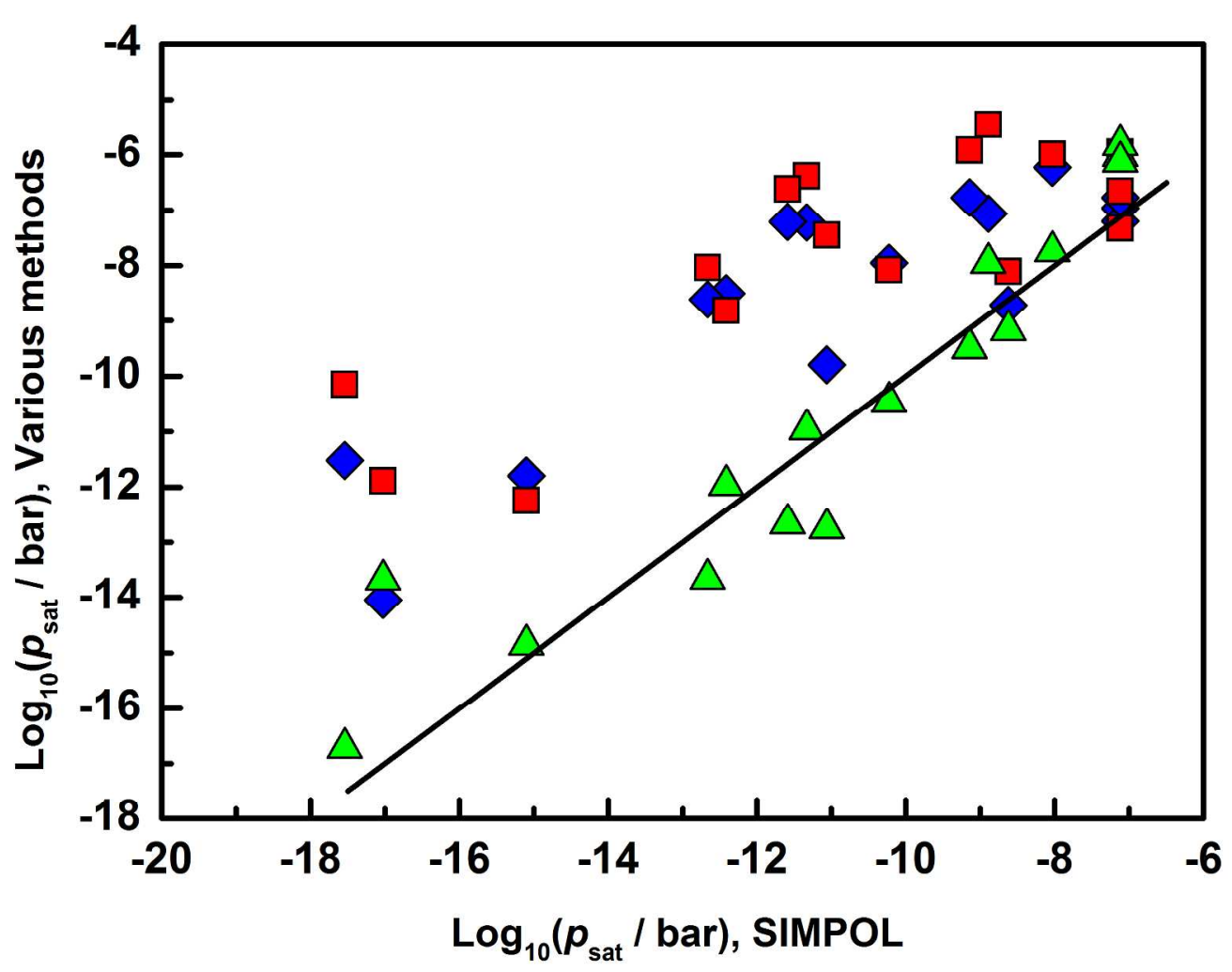

Figure 4. Comparison of saturation vapor pressure predictions (in bar, at $298 \mathrm{~K}$ ) by various methods, versus the group-contribution method SIMPOL. Values are given for COSMOTherm using the BP/TZVP parameterization and multiple conformers (blue diamonds), COSMOTherm using the BP/TZVPD-FINE parameterization and a single conformer (red squares) and the EVAPORATION group-contribution method (green triangles). A 1:1 line is shown in black to aid the comparison.

Compared to the group-contribution methods, COSMOTherm predicts larger differences between positional isomers (where the same functional groups are located on different positions on the carbon chain, e.g. the three $\mathrm{C}_{10} \mathrm{H}_{16} \mathrm{O}_{4}$ isomers), but generally somewhat smaller 
differences between functional group isomers (with the same elemental composition but different functional groups, e.g. the three $\mathrm{C}_{10} \mathrm{H}_{16} \mathrm{O}_{8}$ isomers). Especially the former result is unsurprising, given the limited ability of group-contribution methods to distinguish between positional isomers. By construction, SIMPOL does not distinguish between positional isomers at all. For the HOM monomers, SIMPOL predicts differences between functional group isomers that are mostly larger than those predicted by COSMOTherm, but smaller than those predicted by Nannoolal/Nannoolal or EVAPORATION.

All methods agree that the hydroperoxycarboxylic acids $\mathrm{C}_{10} \mathrm{H}_{16} \mathrm{O}_{6}$-iso2 and $\mathrm{C}_{10} \mathrm{H}_{16} \mathrm{O}_{8}$ iso1 have lower saturation vapor pressures than their hydroxyperoxy acid isomers $\mathrm{C}_{10} \mathrm{H}_{16} \mathrm{O}_{6}$-isol and $\mathrm{C}_{10} \mathrm{H}_{16} \mathrm{O}_{8}$-iso2, respectively, and that the hydroxy-hydroperoxy-carboxylic acid $\mathrm{C}_{10} \mathrm{H}_{16} \mathrm{O}_{7^{-}}$ iso2 has a lower saturation vapor pressure than its hydroperoxy-peroxy acid isomer $\mathrm{C}_{10} \mathrm{H}_{16} \mathrm{O}_{7}$ iso1. In contrast, the methods disagree on the effect of endoperoxide groups on the saturation vapor pressure: Nannoolal/Nannoolal, EVAPORATION, SIMPOL and COSMOTherm using multiple conformers and the BP/TZVPD-FINE parameterization predict that the $\mathrm{C}_{10} \mathrm{H}_{16} \mathrm{O}_{8}$-iso3 structure containing an endoperoxide functional group has a saturation vapor pressure $4 \times 10^{6}$, $3 \times 10^{4}, 1 \times 10^{4}$ or 13 times higher, respectively, than the $\mathrm{C}_{10} \mathrm{H}_{16} \mathrm{O}_{8}$-isol isomer, while the three remaining COSMOTherm approaches predict the opposite (though by less than a factor of 5).

All methods also agree that replacing a carboxylic acid group by a peroxy acid group (i.e. going from $\mathrm{C}_{10} \mathrm{H}_{16} \mathrm{O}_{6}$-iso2 to $\mathrm{C}_{10} \mathrm{H}_{16} \mathrm{O}_{7}$-iso1, from $\mathrm{C}_{10} \mathrm{H}_{16} \mathrm{O}_{7}$-iso2 to $\mathrm{C}_{10} \mathrm{H}_{16} \mathrm{O}_{8}$-iso2, or from $\mathrm{C}_{10} \mathrm{H}_{16} \mathrm{O}_{8}$-iso1 to $\mathrm{C}_{10} \mathrm{H}_{16} \mathrm{O}_{9}$ ) increases the saturation vapor pressure. According to the groupcontribution methods, replacing an alcohol group by a hydroperoxide group (i.e. going from $\mathrm{C}_{10} \mathrm{H}_{16} \mathrm{O}_{7}$-iso2 to $\mathrm{C}_{10} \mathrm{H}_{16} \mathrm{O}_{8}$-iso1, from $\mathrm{C}_{10} \mathrm{H}_{16} \mathrm{O}_{8}$-iso2 to $\mathrm{C}_{10} \mathrm{H}_{16} \mathrm{O}_{9}$, or from $\mathrm{C}_{20} \mathrm{H}_{30} \mathrm{O}_{10}$-iso1 to $\mathrm{C}_{20} \mathrm{H}_{30} \mathrm{O}_{12}$ ) always lowers the saturation vapor pressure. The differences between $\mathrm{OH} / \mathrm{OOH}$ pairs 
predicted by Nannoolal/Nannoolal and EVAPORATION are larger than those predicted by SIMPOL. With COSMOTherm, the effect of the $\mathrm{OH} / \mathrm{OOH}$ substitution depends on the exact approach (single or multiple conformers, BP/TZVP of BP/TZVP-FINE) and the molecules in question. For the monomers, COSMOTherm usually predict fairly small (less than a factor of 2) changes in either direction upon substitution of $\mathrm{OH}$ groups by $\mathrm{OOH}$ groups. In contrast, COSMOTherm predicts the $\mathrm{C}_{20} \mathrm{H}_{30} \mathrm{O}_{12}$ dimer structure with two $\mathrm{OOH}$ groups to have a much higher saturation vapor pressure than the corresponding $\mathrm{C}_{20} \mathrm{H}_{30} \mathrm{O}_{10}$-isol structure with two $\mathrm{OH}$ groups.

As expected, all methods qualitatively predict that the saturation vapor pressure usually tends to decrease with increasing oxidation state. However, the magnitude of this decrease is much smaller (and much more frequently reversed) for the COSMOTherm - based approaches than for the group-contribution methods. For example, the decrease in saturation vapor pressure in going from $\mathrm{C}_{10} \mathrm{H}_{16} \mathrm{O}_{4}$-iso3 to $\mathrm{C}_{10} \mathrm{H}_{16} \mathrm{O}_{9}$, which represent different termination products of the same autoxidation chain (see Fig 12 in Kurtén et al. ${ }^{51}$ ) is less than a factor of 10 according to COSMOTherm (with the BP/TZVPD-FINE - based approaches actually predicting a small increase), but a factor of $2 \times 10^{8}, 3 \times 10^{6}$ and $3 \times 10^{4}$ according to Nannoolal/Nannoolal, EVAPORATION and SIMPOL, respectively. In Figure 5 we illustrate the different trends with respect to oxidation state in a two-dimensional volatility-oxidation space, ${ }^{19}$ plotting the average carbon oxidation states against the saturation vapor pressures predicted by four of the methods for the different $\mathrm{ROOH}$ termination products of the same autoxidation chain. The average carbon oxidation state we use here is the empirical formulation easily derived from mass-spectrometer observations $(\mathrm{OSc}=2 \mathrm{O}: \mathrm{C}-\mathrm{H}: \mathrm{C})$, though the actual oxidation state of carbon is much lower for 
-OOH functional group addition (the second oxygen atom does not increase the carbon oxidation state).

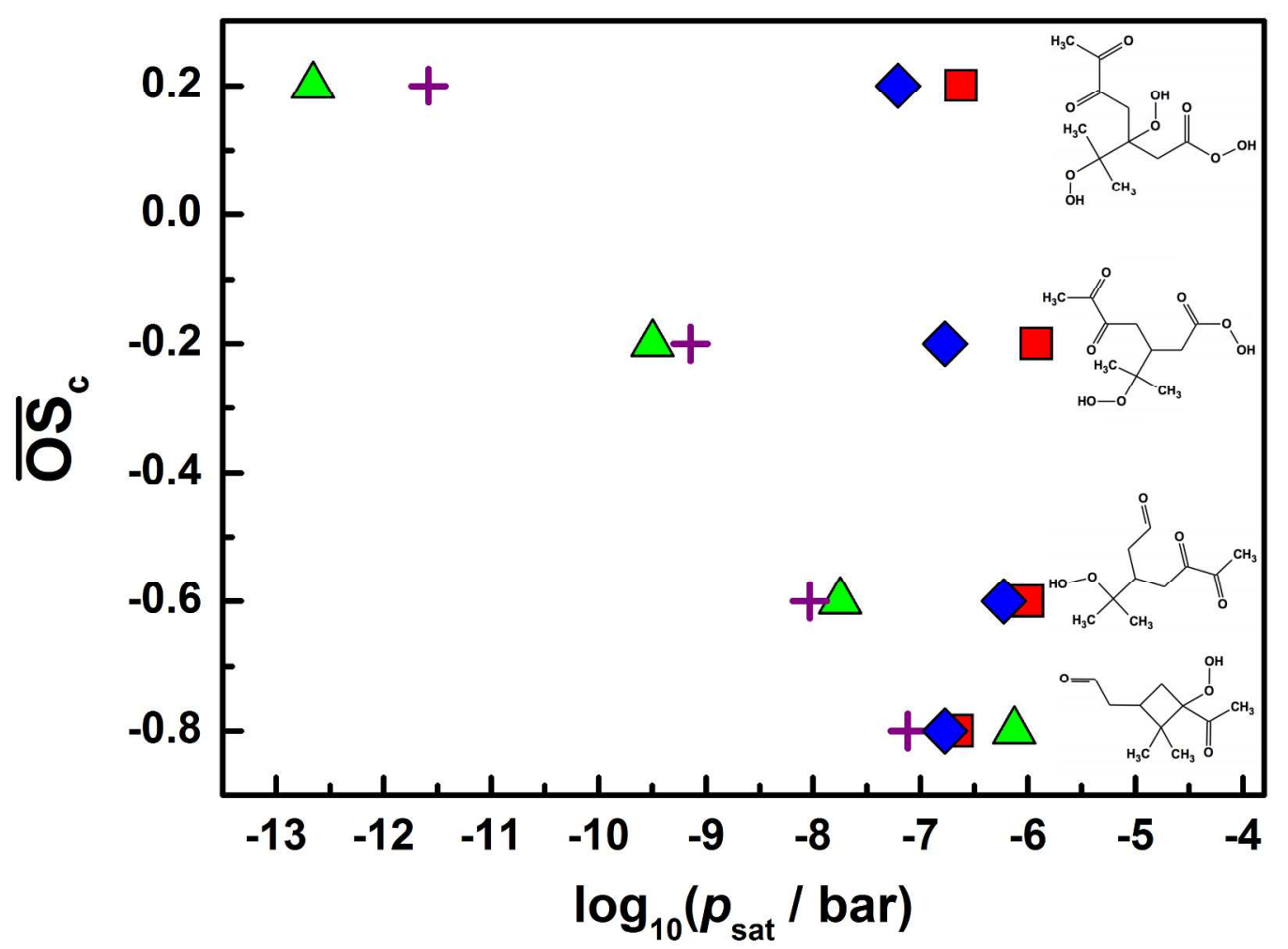

Figure 5. The average carbon oxidation state $\left(\mathrm{OS}_{\mathrm{C}}\right.$, see text for definition) of four autoxidation products $\left(\mathrm{C}_{10} \mathrm{H}_{16} \mathrm{O}_{4}\right.$-iso3, $\mathrm{C}_{10} \mathrm{H}_{16} \mathrm{O}_{5}, \mathrm{C}_{10} \mathrm{H}_{16} \mathrm{O}_{7}$-isol and $\left.\mathrm{C}_{10} \mathrm{H}_{16} \mathrm{O}_{9}\right)$ plotted against the logarithms of the saturation vapor pressure (in bar, at $298 \mathrm{~K}$ ) predicted by four different methods: COSMOTherm using the BP/TZVP parameterization and multiple conformers (blue diamonds), COSMOTherm using the BP/TZVPD-FINE parameterization and a single conformer (red squares), the EVAPORATION group-contribution method (green triangles), and the SIMPOL group-contribution method (purple crosses). The four products (shown schematically in the righthand-side of the figure) are all $\mathrm{ROOH}$ termination products of the same autoxidation chain 
(shown in Fig 12 in Kurtén et al. ${ }^{51}$ ), which involves one bimolecular step forming an alkoxy radical (which promptly leads to ring opening and formation of a keto-alkyl radical) in addition to the peroxy radical $\mathrm{H}$-shifts and $\mathrm{O}_{2}$ additions.

A large part of the difference between COSMOTherm and the other methods is very likely due to its more detailed treatment of intramolecular hydrogen bonds. These tend to stabilize the gas-phase molecules relative to the liquid phase (or even relative to small clusters ${ }^{22}$ ), and thus increase the saturation vapor pressure. In this particular system, breaking of the cyclobutyl ring (in going from $\mathrm{C}_{10} \mathrm{H}_{16} \mathrm{O}_{4}$ to the more highly oxidized products) increases the flexibility of the molecule, and allows for more intramolecular H-bonding as more and more polar functional groups are added. This is illustrated by the difference in saturation vapor pressures of $\mathrm{C}_{10} \mathrm{H}_{16} \mathrm{O}_{4}$-iso3 and $\mathrm{C}_{10} \mathrm{H}_{16} \mathrm{O}_{5}$ (see also Figure 5), which differ only by the absence of a cyclobutyl ring and the presence of a ketone group in the latter structure. All COSMOThermbased approaches predict an increase in the saturation vapor pressure in going from $\mathrm{C}_{10} \mathrm{H}_{16} \mathrm{O}_{4}$ iso3 to $\mathrm{C}_{10} \mathrm{H}_{16} \mathrm{O}_{5}$, as the increased capacity for intramolecular hydrogen bonding outweighs the effect of the ketone group. The group-contribution methods do not account for this increased Hbonding, and thus predict a significant decrease in the saturation vapor pressure.

Due to the intramolecular H-bonds, the decrease in saturation vapor pressures as a function of oxidation state for the studied set of $\alpha$-pinene autoxidation products can be expected to be much smaller than that predicted by the group-contribution methods. The latter are wellknown $^{27,28}$ to overestimate the decrease in volatility due to increasing functionalization, in part due to the limited ability of these methods to account for effects such as intramolecular Hbonding. As can be seen from Figure 3, the HOM candidates in this study contain between 1 and 
3 intramolecular hydrogen bonds. Assuming that each bond stabilizes the molecule in the gas phase (with respect to the liquid phase) by $2-4 \mathrm{kcal} / \mathrm{mol}$ in terms of the free energy, this would imply an increase in the saturation vapor pressure of between a factor of 30 and 900 per H-bond, or by over 8 orders of magnitude for molecules with three internal H-bonds. Due to the lack of group-interaction terms describing the H-bonding of peroxide or peroxy acid groups in the group-contribution methods used here, this effect is entirely neglected in their saturation vapor pressure predictions. The increasing disagreement between COSMOtherm and the groupcontribution methods as a function of the oxidation state of the HOM monomers (see e.g. Figure 5) could thus in principle be entirely due to the neglect of the effect of internal H-bonds by the group-contribution methods.

In the absence of measured saturation vapor pressure data on any HOM-type molecules, it is difficult to evaluate which set of predictions is more reliable in an absolute sense. In addition to the arguments presented above, another possible approach for evaluating the reliability of the different families of predictions is to examine whether or not they are even internally consistent, for example by comparing the effects of small structural changes on the saturation vapor pressures. The Nannoolal/Nannoolal saturation vapor pressure dataset in particular seems to contain some unrealistic predictions. For example, adding just a single $\mathrm{OOH}$ group to $\mathrm{C}_{10} \mathrm{H}_{16} \mathrm{O}_{8^{-}}$ iso3 to form $\mathrm{C}_{10} \mathrm{H}_{16} \mathrm{O}_{10}$ should, according to this method, result in a decrease of the saturation vapor pressure by a factor of 45 000. The single-conformer COSMOTherm predictions of a saturation vapor pressure increase upon $\mathrm{OOH}$ addition are similarly unrealistic, though the magnitude of the effect is much smaller. The multiconformer COSMOTherm and SIMPOL predictions of a decrease of about a factor of 10 and 300, respectively, seem more plausible, while the EVAPORATION prediction of a decrease by a factor of 3700, while high, is not 
completely implausible. Other odd predictions by Nannoolal/Nannoolal include the 15000 - fold difference in saturation vapor pressures predicted for the two $\mathrm{C}_{10} \mathrm{H}_{16} \mathrm{O}_{7}$ isomers (for which all other approaches predict more reasonable differences of 2-3 orders of magnitude), the abovementioned $4 \times 10^{6}$ - fold difference in vapor pressures between $\mathrm{C}_{10} \mathrm{H}_{16} \mathrm{O}_{8}$-iso3 and $\mathrm{C}_{10} \mathrm{H}_{16} \mathrm{O}_{8}$-iso1, and - perhaps oddest of all - the prediction that the saturation vapor pressure of the $C_{20}$ dimers are considerably higher than that of the $\mathrm{C}_{10}$ monomers, despite having twice the number of carbon atoms and an equal or greater number of oxygen atoms. The strange behavior of the Nannoolal/Nannoolal method is likely due to the fact that parameters describing hydroperoxide, endoperoxide or peroxy acid groups are entirely missing from the Nannoolal et al. parameterization, $^{24}$ as also noted (and cautioned) by Compernolle et $a .^{25}$ The Nannoolal/Nannoolal method can therefore not be expected to produce reliable results for molecules containing multiple (or even any) such groups. The parameterization dataset of SIMPOL does not contain multifunctional hydroperoxides or peroxyacids either, but due to its greater simplicity, the method is likely more robust - as indicated by the lack of serious internal inconsistencies in the SIMPOL - predicted saturation vapor pressures. The EVAPORATION method $^{25}$ does contain parameters describing the effect of single hydroperoxide or peroxy acid groups, but does not have sufficient data in the parameterization dataset to describe their interactions with each other (or with other groups). It can therefore be expected to be fairly accurate for the less functionalized monomers, and while it neglects e.g. the effect of intramolecular H-bonds in the more oxidized monomers, its predictions are internally consistent. The more advanced (multiconformer and/or BP/TZVP-FINE) COSMOTherm - based predictions are also free from obvious major internal inconsistencies in the monomer saturation vapor pressures, unless the exceptionally small change in saturation vapor pressure in going from 
$\mathrm{C}_{10} \mathrm{H}_{16} \mathrm{O}_{4}$-iso3 to $\mathrm{C}_{10} \mathrm{H}_{16} \mathrm{O}_{9}$ is counted as such. For the dimers, the large (between 50-fold and 30 000-fold depending on the method) increase in saturation vapor pressure in going from $\mathrm{C}_{20} \mathrm{H}_{30} \mathrm{O}_{10}$-iso1 to $\mathrm{C}_{20} \mathrm{H}_{30} \mathrm{O}_{12}$ could be considered an inconsistency, as the COSMOTherm results for the monomers indicate that replacement of $\mathrm{OH}$ by $\mathrm{OOH}$ groups should not lead to enormous changes in saturation vapor pressures in either direction. This increase is also hard to justify solely in terms of the intramolecular $\mathrm{H}$-bonds of $\mathrm{C}_{20} \mathrm{H}_{30} \mathrm{O}_{12}$, as also the $\mathrm{C}_{20} \mathrm{H}_{30} \mathrm{O}_{10}$-isol molecule contains two internal H-bonds, though these might - especially relative to the intermolecular bonds in the liquid phase - be weaker due to the more limited flexibility of the $\mathrm{OH}$ groups. It seems likely that while the group-contribution methods neglect the effects of intramolecular $\mathrm{H}$ bonds on the HOM saturation vapor pressures, COSMOTherm may be overestimating these effects, possibly due to its limited ability to model the rearrangement of molecular structures toward their optimal intermolecular H-bonding patterns in the liquid phase. This is supported by the observation that COSMOTherm somewhat overestimates the saturation vapor pressures of all the molecules in our test-set (Table 1) which possess both conformational flexibility, and the ability to form intramolecular H-bonds.

Based on a cautious interpretation of the literature benchmarks and our limited atmospherically relevant test-set (Table 1), the error margins of the COSMOTherm saturation vapor pressures for the exotic multifunctional HOM molecules are probably at least around a factor of 100 , with overprediction being more likely than underprediction. As the SIMPOL method neglects any position-dependent interactions between functional groups (e.g. intramolecular H-bonds, which are certainly present in these systems, as indicated by Figure 3), it likely has at least a similar error margin for these multifunctional compounds. The Nannoolal/Nannoolal predictions, as mentioned above, should probably be disregarded due to 
this method's lack of parameters describing the studied functional groups. The EVAPORATION predictions for these compounds should certainly be better than the Nannoolal/Nannoolal ones, but as suggested by Valorso et $a .^{28}$ and O'Meara et al. ${ }^{27}$, they likely significantly underestimate the saturation vapor pressures of the most highly oxidized (and thus functionalized) compounds, in this case mainly due to the neglect of intramolecular H-bonds. The same very probably applies also to SIMPOL. The error margin of the EVAPORATION method is thus unlikely to be any smaller than that of COSMOTherm or SIMPOL, at least for the more highly oxidized monomers, or for the dimers.

The COSMOTherm, EVAPORATION and SIMPOL saturation vapor pressure predictions for the monomers are thus all compatible with each other, in the sense of their (admittedly large) likely error margins overlapping. For the dimers, the differences between the COSMOTherm-based and group-contribution predictions (ignoring the probably unreliable Nannoolal/Nannoolal method) are both larger, and harder to explain in terms of structural features. In contrast to the most highly oxidized monomers with three intramolecular H-bonds, $\mathrm{C}_{20} \mathrm{H}_{30} \mathrm{O}_{10}$-iso2 contains only one, and the two other dimers two, intramolecular H-bonds. It therefore seems unlikely that these would account for all of the (at worst over $10^{7}-$ fold) differences between the COSMOTherm-based predictions and the group-contribution methods. Also, as mentioned previously, the COSMOTherm predictions for the dimers are internally somewhat inconsistent. In the absence of any convincing explanations for the differences between the predicted saturation vapor pressures for the HOM dimers, we can only note that they are chemically quite different from any of the molecules in the parameterization datasets of any of the methods used here (including COSMO-RS), and that saturation vapor pressure data for molecules of this size (and likely volatility) are in general very scarce. ${ }^{20}$ The error margins of all 
of the methods may therefore be even larger for the dimers than for the monomers. Nevertheless, due to the likelihood of COSMOTherm overpredicting and EVAPORATION (or SIMPOL) underpredicting the saturation vapor pressures, the true saturation vapor pressures of both the monomers and the dimers should very probably lie between the minimum and maximum values presented in Tables 2 and 3.

Wania et al. ${ }^{34}$ suggest that the partitioning coefficient $K_{i, \text { WIOM }}$ for an organic compound $i$ between the gas phase and a phase composed of water-insoluble organic matter (WIOM) may be a more robust predictor of the gas-particle partitioning behavior of the compound than its saturation vapor pressure, as predictions by different methods for $K_{i, W I O M}$ generally vary less than the predicted saturation vapor pressures. Using COSMOTherm, $K_{i, W I O M}$ can be calculated either directly (as a Henry's Law constant in the desired WIOM phase), or indirectly, by computing separately the saturation vapor pressures and the activity coefficients in a suitable (single- or multicomponent) WIOM phase, as described by Arp and Goss (Eq 5 in their study). ${ }^{55}$ The results of the two approaches are identical. As we have already computed the saturation vapor pressures, we employed the indirect approach in this study. Using the standard BP/TVZP parameterization and multiple conformers, we computed the activity coefficients of all 16 products shown in Figure 2 in a WIOM phase composed of the model compound "B" proposed by Kalberer et al. ${ }^{56}$, and also used in both Arp and Goss ${ }^{55}$ and Wania et al. ${ }^{34}$ (We included all six conformers found for this molecule in the calculations.) The activity coefficients (at infinite dilution and $298 \mathrm{~K}$ ) of the autoxidation products in the model WIOM phase varied between 0.59 and 2.01 , with the more oxidized structures generally tending to have lower activity coefficients. This small variation indicates that for the particular set of compounds studied here, and assuming order-ofmagnitude validity of the result that the computed activity coefficients are close to unity, using 
partitioning coefficients instead of saturation vapor pressures is unlikely to significantly reduce the differences between the predictions on the extent of gas-particle partitioning. The results further suggest that equilibrium phase partitioning is likely to be strongly correlated with the saturation vapor pressure also for atmospheric autoxidation products. The activity coefficients in water, computed with the same approach, varied between 220 and 12000 for the "monomers" and between 93000 and 790000 for the "dimers", indicating that especially the latter are indeed water-insoluble, and that $K_{i, \text { ШІом }}$ is thus the appropriate coefficient to describe their partitioning.

\section{Conclusions and atmospheric implications}

For evaluating the atmospheric fate and impact of HOMs and other autoxidation products, one crucial question is whether or not their saturation vapor pressures are low enough to qualify them as ELVOCs, or alternatively LVOCs. Vapors with saturation vapor pressures around or below $10^{-14}$ bar are usually considered to be effectively non-volatile (i.e. "ELVOC"), whereas saturation vapor pressures much higher than this generally prevent homogeneous nucleation due to the Kelvin effect, and also indicate that re-evaporation back into the gas phase can not be neglected from nanometer-scale particles. ${ }^{19}$ Saturation vapor pressures around $10^{-10}$ bar, on the other hand, are sufficient to contribute to the growth of larger aerosol particles.

According to the COSMOTherm results, none of the autoxidation products studied here (with the possible exception of $\mathrm{C}_{20} \mathrm{H}_{30} \mathrm{O}_{10}$-iso1) are genuine ELVOCs. If we account for the fact that the COSMOTherm predictions for these molecules are likely overestimates (by up to a factor of 100 or so), and that the true saturation vapor pressures are probably found somewhere between the COSMOTherm and the group-contribution predictions, then all of the HOM dimers may well be ELVOCs. In contrast, none of the studied "HOM monomer" structures are ELVOCs 
according to any of the reliable methods used here. The Nannoolal/Nannoolal predictions for HOM - type molecules, as discussed above, should likely be disregarded - and it is worth noting that if they were to be accepted at face value, then the HOM dimers would no longer be ELVOCs, and some dimers would hardly even be LVOCs. However, the more oxidized monomers are likely still LVOCs, as their saturation vapor pressures, after accounting for the probable overestimation by COSMOTherm, are likely roughly around $10^{-10}$ bar.

While the COSMOTherm saturation vapor pressures are not quantitatively reliable, the benchmarking performed both here and in literature studies indicates that they are unlikely to be wrong by many orders of magnitude, as COSMOTherm - unlike the group-contribution methods when applied to systems very different to their parametrization dataset - models the actual chemical interactions of the real molecular systems, including the crucially important intramolecular hydrogen bonds. Thus, we can state the following tentative conclusions:

1)Group-contribution methods very likely generally underestimate the volatility of atmospheric autoxidation products, largely by ignoring intramolecular H-bonds. Conversely, COSMOTherm may somewhat overestimate the effect of these H-bonds and thus the saturation vapor pressures. Without any other basis for recommendation, we suggest using a geometric average of COSMOTherm and SIMPOL saturation vapor pressures for autoxidation products, with the COSMOTherm representing the likely maximum and SIMPOL the likely minimum saturation vapor pressure.

2)“HOM" monomers formed in $\alpha$-pinene autoxidation are unlikely to be ELVOCs (i.e. have saturation vapor pressures around or below $10^{-14}$ bar) even when their $\mathrm{O}: \mathrm{C}$ ratios are close to 1. 
However, they are likely to be LVOCs (i.e. have saturation vapor pressures around or below $10^{-}$ 10 bar).

3)The less oxidized products of $\alpha$-pinene autoxidation are highly unlikely to be ELVOCs, and may not even be LVOCs.

4) HOM dimers may well be ELVOCs, but even this should not be assumed with certainty.

The relatively high saturation vapor pressures computed here do not rule out a significant contribution of HOMs to SOA formation and/or aerosol growth, nor do they contradict the many experimental indications of such a contribution. Laboratory experiments ${ }^{10}$ demonstrate that HOMs formed in $\alpha$-pinene ozonolysis condense (adsorb) effectively onto both chamber walls and seed particles, and both HOMs and their decomposition products have recently been detected in the particle phase. ${ }^{16}$ If HOMs indeed turn out not to be ELVOCs, this simply suggests either that HOMs mainly contribute to the condensational growth of larger particles (with diameters well above a few nanometers), and/or that the mechanism by which HOMs contribute to particle growth involves chemical reactions in addition to simple physical condensation or absorption. Recent AMS measurements indicate that HOMs undergo rapid chemical reactions after partitioning into particles. ${ }^{57}$ Provided that these reactions convert the HOMs into less volatile form, such reactive uptake could significantly increase their contributions to particle growth.

\title{
Corresponding Author
}

*theo.kurten@helsinki.fi, Tel. +358 505260123

\author{
ACKNOWLEDGMENT
}


We thank the Academy of Finland for funding and the CSC IT Centre for Science for computer time. T. K. thanks prof. Frank Wania for advice on partitioning coefficient calculations. NMD was supported by grant CHE1412309 from the US National Science Foundation.

\section{ASSOCIATED CONTENT}

The Supporting Information is available free of charge on the ACS Publications website at DOI: 10.1021/acs.jpca.XXXXX.

Structures and group-contribution saturation vapor pressures for the test molecules, description of the chemical reactions leading from $\alpha$-pinene ozonolysis to the studied molecules, zip archive with cosmo files and gas-phase energies for all studied compounds.

\section{References}

\footnotetext{
${ }^{1}$ Donahue, N. M.; Kroll, J. H.; Pandis, S. N.; Robinson, A. L. A two-dimensional volatility basis set - Part 2: Diagnostics of organic-aerosol evolution. Atmos. Chem. Phys. 2012, 12, 615634.

2 Jimenez, J. L.; Canagaratna, M. R.; Donahue, N. M.; Prevot, A. S.; Zhang, Q.; Kroll, J. H.; DeCarlo, P. F.; Allan, J. D.; Coe, H.; Ng, N. L., et al. Evolution of Organic Aerosols in the Atmosphere. Science 2009, 326, 1525-1529.

3 Silva, R. A.; West, J. J.; Zhang, Y.; Anenberg, S. C.; Lamarque, J.-F.; Shindell, D. T.; Collins, W. J.; Dalsoren, S.; Faluvegi, G.; Folberth, G. Global Premature Mortality Due to
} 
Anthropogenic Outdoor Air Pollution and the Contribution of Past Climate Change. Environ. Res. Lett. 2013, 8, 034005.

${ }^{4}$ Kroll, J. H.; Seinfeld, J. H. Chemistry of Secondary Organic Aerosol: Formation and Evolution of Low-volatility Organics in the Atmosphere. Atmos. Environ. 2008, 42, 3593-3624.

${ }^{5}$ Donahue, N. M.; Robinson, L.; Trump, E. R.; Riipinen, I.; Kroll, J. H. Volatility and Aging of Atmospheric Organic Aerosol. Top. Curr. Chem. 2014, 339, 97-143.

${ }^{6}$ Seinfeld, J. S.; Pandis, S. N. Atmospheric Chemistry and Physics: From Air Pollution to Climate Change, 2nd ed. Wiley-Interscience, USA, 2006.

${ }^{7}$ Orlando, J. J.; Tyndall, G. S. Laboratory Studies of Organic Peroxy Radical Chemistry: an Overview with Emphasis on Recent Issues of Atmospheric Significance. Chem. Soc. Rev. 2012, $41,6294-6317$

${ }^{8}$ Donahue, N. M.; Hartz, K. E. H.; Chuong, B.; Presto, A. B.; Stanier, C. O.; Rosenørn, T.; Robinson, A. L.; Pandis, S. N. Critical factors determining the variation in SOA yields from terpene ozonolysis: A combined experimental and computational study. Faraday Discuss. 2005, $130,295-310$.

9 Crounse, J. D.; Nielsen, L. B.; Jørgensen, S.; Kjaergaard, H. G.; Wennberg, P. O. Autooxidation of Organic Compounds in the Atmosphere. J. Phys. Chem. Lett. 2013, 4, 35133520. 
${ }^{10}$ Ehn, M.; Thornton, J. A.; Kleist, E.; Sipilä, M.; Junninen, H.; Pullinen, I.; Springer, M.; Rubach, F.; Tillmann, R.; Lee, B.; et al. A Large Source of Low-Volatility Secondary Organic Aerosol. Nature 2014, 506, 476-479.

${ }^{11}$ Rissanen, M. P.; Kurtén, T.; Sipilä; M.; Thornton, J. A.; Kangasluoma, J.; Sarnela, N.; Junninen, H.; Jørgensen, S.; Schallhart, S.; Kajos, M. K.; et al. The Formation of Highly Oxidized Multifunctional Products in the Ozonolysis of Cyclohexene. J. Am. Chem. Soc. 2014, $136,15596-15606$.

${ }^{12}$ Mentel, T. F.; Springer, M.; Ehn, M.; Kleist, E.; Pullinen, I.; Kurtén, T.; Rissanen, M.; Wahner, A.; Wildt, J. Formation of Highly Oxidized Multifunctional Compounds: Autoxidation of Peroxy Radicals Formed in the Ozonolysis of Alkenes - Deduced from Structure-Product Relationships. Atmos. Chem. Phys. 2015, 15, 6745-6765.

13 Jokinen, T.; Sipilä, M.; Richters, S.; Kerminen, V.-M.; Paasonen, P.; Stratmann, F.; Worsnop, D.; Kulmala, M.; Ehn, M.; Herrmann, H.; et al. Rapid Autoxidation Forms Highly Oxidized $\mathrm{RO}_{2}$ Radicals in the Atmosphere. Angew. Chem. Internat. Ed. 2014, 53, 14596-14600.

14 Rissanen, M.; Kurtén, T.; Sipilä, M.; Thornton, J. A.; Kausiala, O.; Garmash, O.;. Kjaergaard, H. G.; Petäjä, T.; Worsnop, D. R.; Ehn, M.; et al. Effects of Chemical Complexity on the Autoxidation Mechanisms of Endocyclic Alkene Ozonolysis Products: From Methylcyclohexenes toward Understanding $\alpha$-Pinene. J. Phys. Chem. A 2015, 119, 4633-4650.

${ }^{15}$ Berndt, T.; Richters, S.; Kaethner, R.; Voigtländer, J.; Stratmann, F.; Sipilä, M.; Kulmala, M.; Herrmann, H. Gas-Phase Ozonolysis of Cycloalkenes: Formation of Highly Oxidized $\mathrm{RO}_{2}$ 
Radicals and Their Reactions with $\mathrm{NO}, \mathrm{NO}_{2}, \mathrm{SO}_{2}$, and Other $\mathrm{RO}_{2}$ Radicals. J. Phys. Chem. A 2015, 119, 10336-10348.

\begin{abstract}
${ }^{16}$ Mutzel, A.; Poulain, L.; Berndt, T.; Iinuma, Y.; Rodigast, M.; Böge, O.; Richters, S.; Spindler, G.; Sipilä, M.; Jokinen, T.; et al. Highly Oxidized Multifunctional Organic Compounds Observed in Tropospheric Particles: A Field and Laboratory Study, Environ. Sci. Technol. 2015, $49,7754-7761$.
\end{abstract}

${ }^{17}$ Peeters, J.; Müller, J.-F. $\mathrm{HO}_{\mathrm{x}}$ Radical Regeneration in Isoprene Oxidation via Peroxy Radical
Isomerisations. II: Experimental Evidence and Global Impact. Phys. Chem. Chem. Phys. 2010, $12,14227-14235$.

${ }^{18}$ Vereecken, L.; Müller, J.-F.; Peeters, J. Low-Volatility Poly-Oxygenates in the OH-Initiated Atmospheric Oxidation of $\alpha$-pinene: Impact of Non-Traditional Peroxyl Radical Chemistry. Phys. Chem. Chem. Phys. 2007, 9, 5241-5248.

${ }^{19}$ Donahue, N. M.; Ortega, I. K.; Chuang, W.; Riipinen, I.; Riccobono, F.; Schobesberger, S.; Dommen, J.; Baltensperger, U.; Kulmala, M.; Worsnop, D. R.; et al. How do organic vapors contribute to new-particle formation? Faraday Discuss. 2013, 165, 91-104.

${ }^{20}$ Bilde, M.; Barsanti, K.; Booth, M.;. Cappa, C. D.; Donahue, N. M.; Emanuelsson, E. U.; McFiggans, G.; Krieger, U. K.; Marcolli, C.; Topping, D., et al. Saturation Vapor Pressures and Transition Enthalpies of Low- Volatility Organic Molecules of Atmospheric Relevance: From Dicarboxylic Acids to Complex Mixtures. Chem. Rev. 2015, 115, 4115-4156. 
${ }^{21}$ Kroll, J. H.; Donahue, N. M.; Jimenez, J. L.; Kessler, S. H.; Canagaratna, M. R.; Wilson, K. R.; Altieri, K. E.; Mazzoleni, L. R.; Wozniak, A. S.; Bluhm, H.; et al. Carbon oxidation state as a metric for describing the chemistry of atmospheric organic aerosol. Nature Chemistry 2011, 3, 133-139.

${ }^{22}$ Elm, J.; Myllys, N; Hyttinen, N.; Kurtén, T. Computational Study of the Clustering of a Cyclohexene Autoxidation Product $\mathrm{C}_{6} \mathrm{H}_{8} \mathrm{O}_{7}$ with Itself and Sulfuric Acid. J. Phys. Chem. A 2015, $119,8414-8421$.

${ }^{23}$ Pankow, J. F.; Asher, W. E. SIMPOL.1: a simple group-contribution method for predicting vapor pressures and enthalpies of vaporization of multifunctional organic compounds. Atmos. Chem. Phys. 2008, 8, 2773-2796.

${ }^{24}$ Nannoolal, Y.,; Rarey, J.; Ramjugernath, D. Estimation of pure component properties. Part 3. Estimation of the vapor pressure of non-electrolyte organic compounds via groupcontributions and group interactions. Fluid Phase Equilibr. 2008, 269, 117-133.

\footnotetext{
${ }^{25}$ Compernolle, S.; Ceulemans, K.; Müller, J.-F. Technical Note: Vapor pressure estimation methods applied to secondary organic aerosol constituents from $\alpha$-pinene oxidation: an intercomparison study. Atmos. Chem. Phys. 2010, 10, 6271-6282.

${ }^{26}$ Compernolle, S.; Ceulemans, K.; Müller, J.-F. EVAPORATION: a new vapour pressure estimation methodfor organic molecules including non-additivity and intramolecular interactions. Atmos. Chem. Phys. 2011, 11, 9431-9450.
} 


\begin{abstract}
${ }^{27}$ O’Meara, S.; Booth, A. M.; Barley, M. H.; Topping, D.; McFiggans, G. An assessment of vapour pressure estimation methods. Phys.Chem.Chem.Phys., 2014, 16, 19453 .

${ }^{28}$ Valorso, R.; Aumont, B.; Camredon, M.; Raventos-Duran, T.; Mouchel-Vallon, C.; Ng, N. L.; Seinfeld, J. H.; Lee-Taylor, J.; Madronich, S. Explicit modelling of SOA formation from $\alpha-$ pinene photooxidation: sensitivity to vapour pressure estimation. Atmos. Chem. Phys. 2011, 11, 6895-6910.
\end{abstract}

${ }^{29}$ Klamt, A.; Eckert, F. COSMO-RS: a novel and efficient method for the a priori prediction of thermophysical data of liquids. Fluid Phase Equilibria 2000, 172, 43-72 (Erratum in Fluid Phase Equilibria 2003, 205, 357)

${ }^{30}$ Eckert, F.; Klamt, A. Fast solvent screening via quantum chemistry: COSMO-RS approach. AlChe Journal 2002, 48, 369-385.

${ }^{31}$ Ahlrichs, R.; Bär, M.; Häser, M.; Horn, H.; Kölmel, C. Electronic Structure Calculations on Workstation Computers: The Program System TURBOMOLE. Chem. Phys. Letters 1989, 162, $165-169$.

\footnotetext{
32 TURBOMOLE V6.6, a development of University of Karlsruhe and Forschungszentrum Karlsruhe GmbH, 1989-2007, TURBOMOLE GmbH, since 2007; available from http://www.turbomole.com, 2014.

${ }^{33}$ Eckert, F.; Klamt, A, COSMOTherm, Version C3.0, Release 15.01; COSMOlogic GmbH \& Co. KG, Leverkusen, Germany, 2014.
} 


\begin{abstract}
${ }^{34}$ Wania, F.; Lei, Y. D.; Wang, C.; Abbatt, J. P. D.; Goss, K.-U. Novel methods for predicting gas-particle partitioning during the formation of secondary organic aerosol. Atmos. Phys. Chem. 2014, 14, 13189-13204.

35 Tomasi, J.; Mennucci, B.; Cami, R. Quantum mechanical continuum solvation models. Chem. Rev. 2005, 105, 2999-3093.

\author{
${ }^{36}$ Spartan 14; Wavefunction Inc.: Irivine CA, 2014
}

${ }^{37}$ COSMOlogic White Paper: Conformations, Relevance and Examples. http://www.cosmologic.de/files/downloads/white-papers/Example_conformer_relevance.pdf.
\end{abstract}
38 Schäfer, A.; Huber, C.; Ahlrichs, R. Fully Optimized Contracted Gaussian Basis Sets of Triple Zeta Valence Quality for Atoms Li to Kr. J. Chem. Phys. 1994, 100, 5829-5835.
${ }^{39}$ Eckert, F. COSMOTherm reference manual. Cosmologic Gmbh, 2015. Available online at: http://www.cosmologic.de/files/downloads/manuals/COSMOTherm_Manual.pdf.

40 Topping, D. UManSysProp Multiphase system online property prediction; http://umansysprop.seaes.manchester.ac.uk.
${ }^{41}$ Nannoolal, Y.; Rarey, J.; Ramjugernath, D.; Cordes, W. Estimation of pure component properties Part 1, Estimation of the normal boiling point of non-electrolyte organic compounds via group-contributions and group interactions. Fluid Phase Equilibr. 2004, 226, 45-63.
${ }^{42}$ O’Boyle, N. M.; Manck, M.; James, C. A.; Morley, C.; Vandermeersch, T.; Hutchison, G. R. Open Babel: An open chemical toolbox. J. Cheminf. 2011, 3, 33


${ }^{43}$ Klamt, A. The COSMO and COSMO-RS solvation models. Wiley Interdisciplinary Reviews: Computational Molecular Science 2011, 1, 699-709.

${ }^{44}$ Gasawi, A. Evaluating COSMO-RS for Vapor-Liquid Equilibrium and Turbomole for Ideal Gas Properties. MSc Thesis, University of Akron, Dept. Of Chemical Engineering, 2007. Downloaded from: http://rave.ohiolink.edu/etdc/view?acc num=akron1196731182, 11.01.2016

${ }^{45}$ Klamt, A.; Mennucci, B.; Tomasi, J.; Barone, V.; Curutchet, C.; Orozco, M.; Luque, F. J. On the Performance of Continuum Solvation Methods. A Comment on "Universal Approaches to Solvation Modeling”. Acc. Chem. Res. 2009, 42, 489-492.

${ }^{46}$ Gharagheizi, F.; Eslamimanesh, A.; Ilani-Kashkouli, P.; Mohammadi, A. H.; Richon, D. Determination of Vapor Pressure of Chemical Compounds: A Group-contribution Model for an Extremely Large Database. Industrial \& Engineering Chemistry Research 2012, 51, 7119-7125.

47 Shiu, W.-Y.; Mackay, D. Henry's Law Constants of Selected Aromatic Hydrocarbons, Alcohols, and Ketones. J. Chem. Eng. Data 1997, 42, 27-30.

${ }^{48}$ Verschueren, K. Handbook of Environmental Data on Organic Chemicals, 2nd ed., Van NostrandReinhold Co., Inc., New York, NY, USA, 1983. (Cited by the National Toxicology $\begin{array}{llll}\text { Program } & \text { Executive } & \text { Summary } & \text { Butylcatechol; }\end{array}$ https://ntp.niehs.nih.gov/testing/status/background/execsumm/b/butylcatechol/index.html)

\footnotetext{
${ }^{49}$ Booth, A. M.; Montague, W. J.; Barley, M. H.; Topping, D. O.; McFiggans G.; Garforth, A.; Percival, C. J. Solid state and sub-cooled liquid vapour pressures of cyclic aliphatic dicarboxylic acids. Atmos. Chem. Phys. 2011, 11, 655-665.
} 
${ }^{50}$ Daubert, T.E.; Danner R.P. Physical and Thermodynamic Properties of Pure Chemicals: Data Compilation, Hemisphere Pub Corp, NY, USA, 1989.

${ }^{51}$ Kurtén, T.; Rissanen, M. P.; Mackeprang, K.; Thornton, J. A.; Hyttinen, N.; Jørgensen, S.; Ehn, M.; Kjaergaard, H. A Computational Study of Hydrogen Shifts and Ring-Opening Mechanisms in a-pinene Ozonolysis Products. J. Phys. Chem. A 2015, 119, 11366-11375.

${ }^{52}$ Vereecken, L.; Peeters, J. A. Structure-Activity Relationship for the Rate Coefficient of HMigration in Substituted Alkoxy Radicals. Phys. Chem. Chem. Phys. 2010, 12, 12608-12620.

${ }^{53}$ Jørgensen, S.; Knap, H. C.; Otkjær, R. V.; Jensen, A. M.; Kjeldsen, M. L. H.; Wennberg, P. O.; Kjaergaard, H. G. Rapid Hydrogen Shift Scrambling in Hydroperoxy-Substituted Organic Peroxy Radicals. J. Phys. Chem. A. 2016, 120, 266-275.

\footnotetext{
${ }^{54}$ Nguyen, T. L.; Peeters, J.; Vereecken, L. Theoretical Study of the Gas-Phase Ozonolysis of ß-pinene. Phys. Chem. Chem. Phys. 2009, 11, 5643- 5656.

55 Arp, H. P. H.; Gos, K.-U. Ambient Gas/Particle Partitioning. 3. Estimating Partition Coefficents of Apolar, Polar, and Ionizable Organic Compounds by Their Molecular Structure. Environ. Sci. Tech. 2009, 43, 1923-2929.

${ }^{56}$ Kalberer, M.; Paulsen, D.; Sax, M.; Steinbacher, M.; Dommen, J.; Prevot, A. S. H.; Fisseha, R.; Weingartner, E.; Frankevich, V.; Zenobi, R.; et al. Identification of polymers as major components of atmospheric organic aerosols. Science, 2004, 303, 1659-1662.
} 
${ }^{57}$ Zhang, X.; McVay, R.; Huang, D. D.; Dalleska, N. F.; Aumont, B.; Flagan, R. C.; Seinfeld, J. H. Formation and evolution of molecular products in a-pinene secondary organic aerosol. Proc. Natl. Acad. Sci. 2015, 112, 14168-14173. 


\section{Table of Contents (TOC) Image}

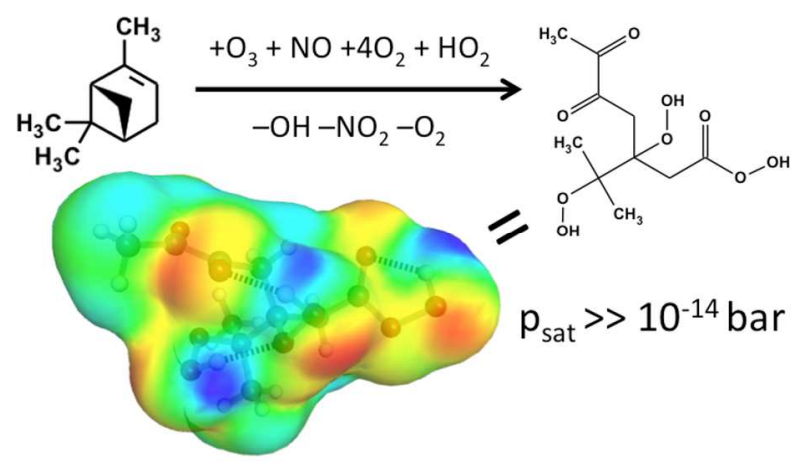


1

2

3

4

5

6

7

8

9

10

11

12

13

14

15

16

17

18

19

20

21

22

23

24

25

26

27

28

29

30

31

32

33

34

35

36

37

38

39

40

41

42

43

44

45

46

47

48

49

50

51

52

53

54

55

56

57

58

59

60
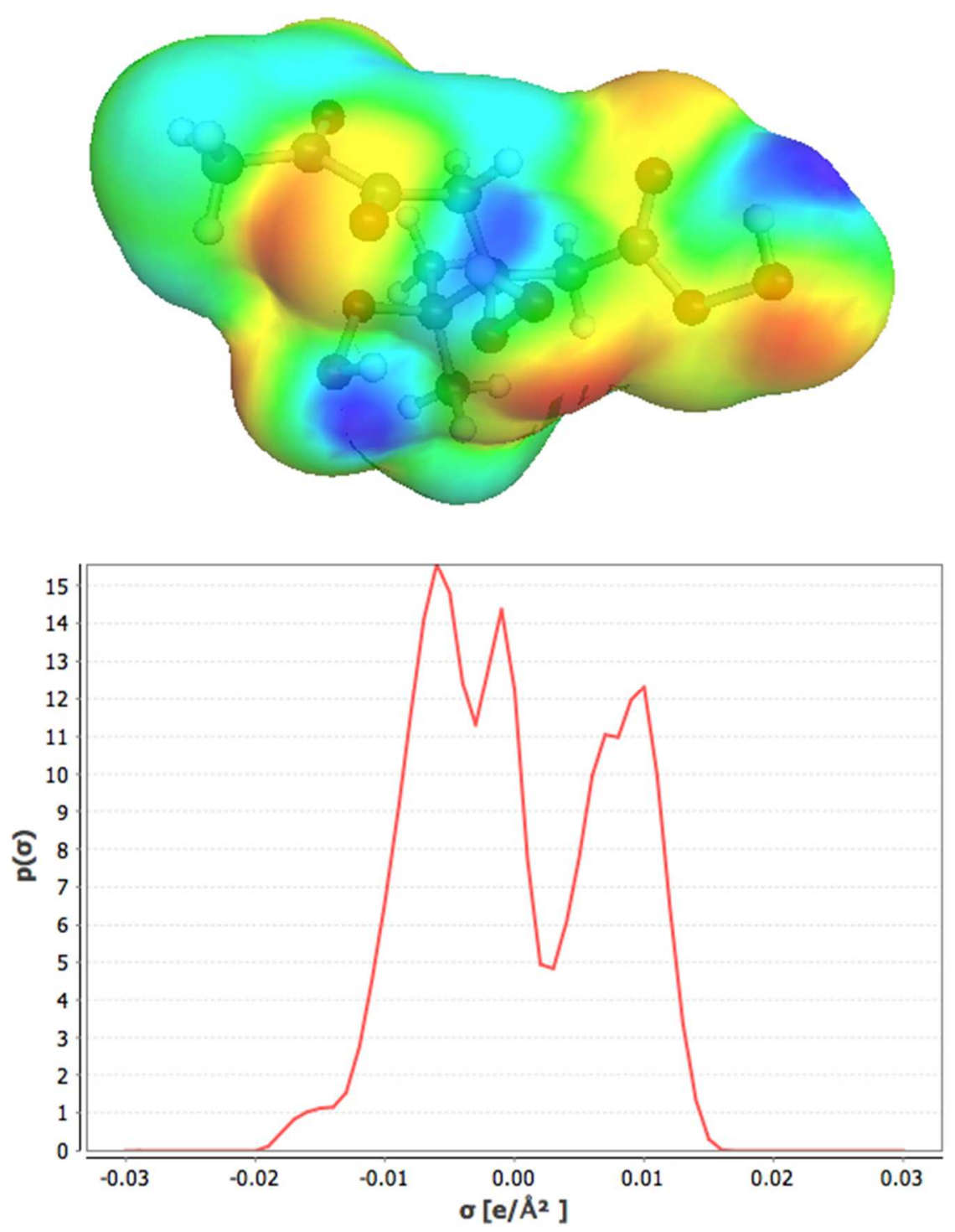

Figure 1

$50 \times 64 \mathrm{~mm}(300 \times 300$ DPI $)$ 


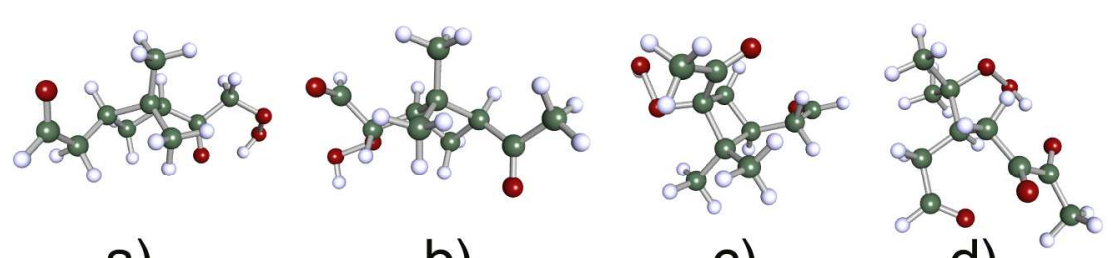

a)

b)

c)

d)

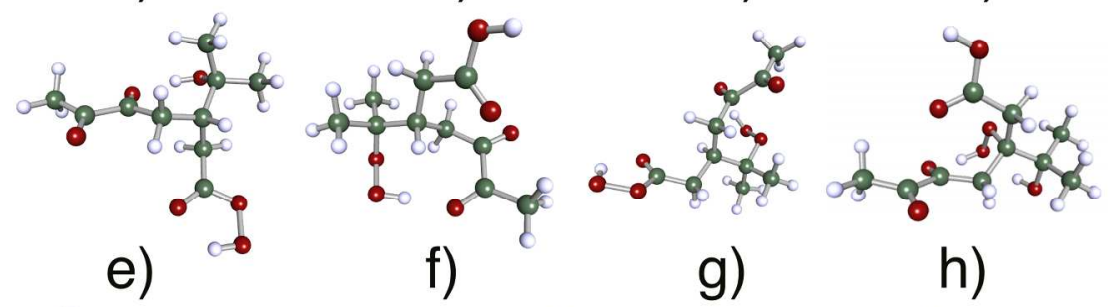

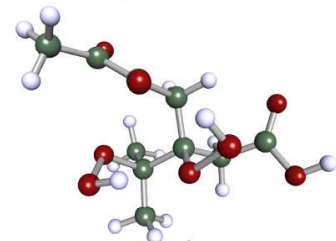

i)

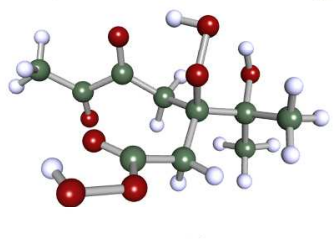

j)

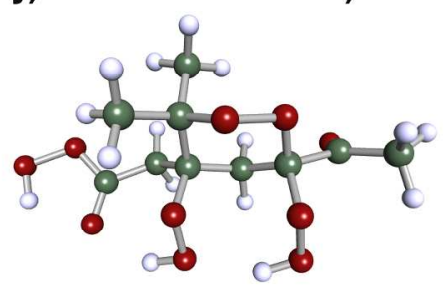

I)

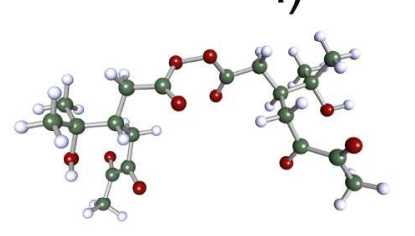

n)

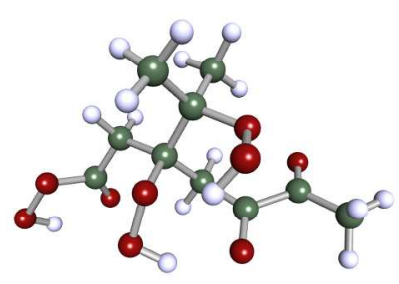

Figure 3

$169 \times 237 \mathrm{~mm}(300 \times 300$ DPI $)$

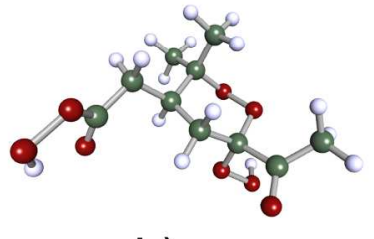

k)

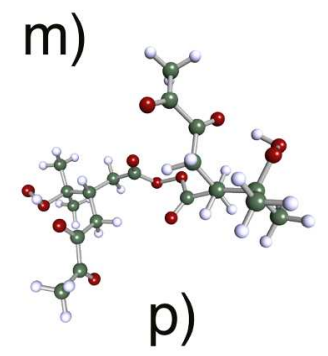




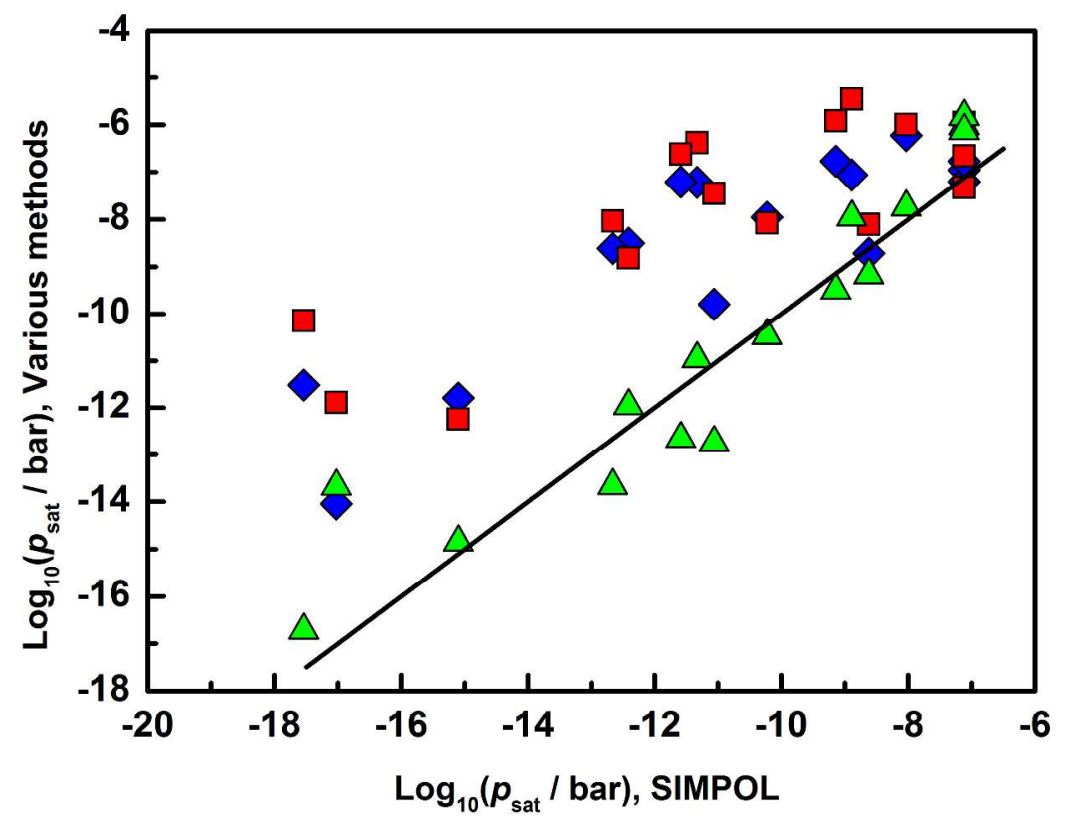

Figure 4

$296 \times 209 \mathrm{~mm}(300 \times 300$ DPI $)$ 


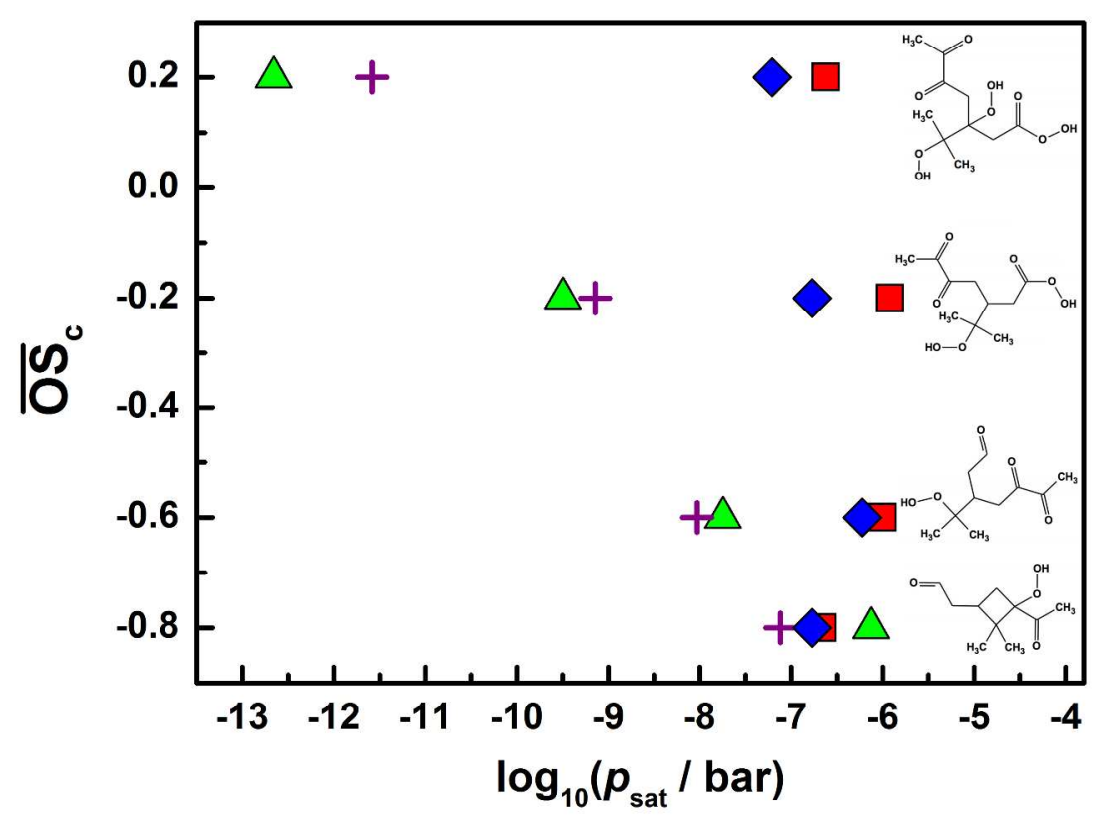

Figure 5

$296 \times 209 \mathrm{~mm}(300 \times 300$ DPI $)$ 


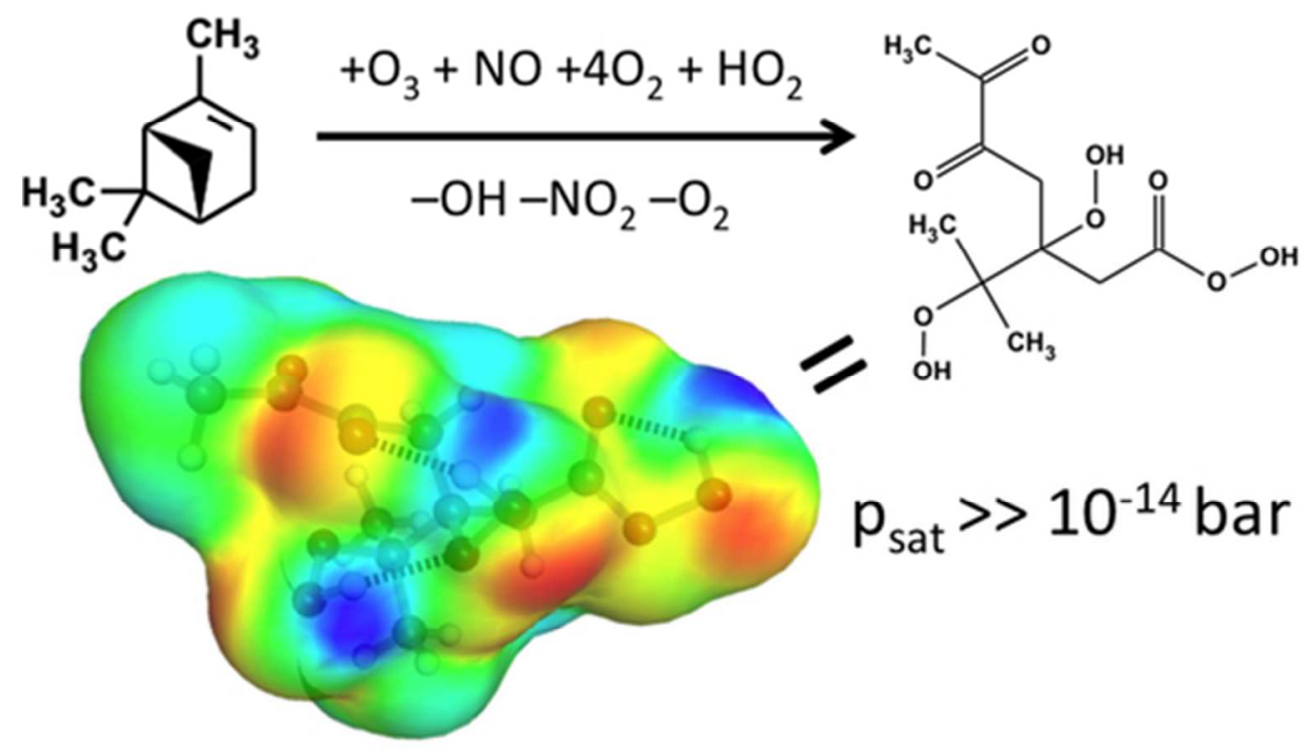

TOC image

$46 \times 27 \mathrm{~mm}(300 \times 300 \mathrm{DPI})$ 